\title{
Elements of effective palliative care models: a rapid review
}

Tim Luckett ${ }^{1,2,3^{*}}$, Jane Phillips ${ }^{2,4,5}$, Meera Agar ${ }^{3,6,7}$, Claudia Virdun², Anna Green² and Patricia M Davidson 2,8

\begin{abstract}
Background: Population ageing, changes to the profiles of life-limiting illnesses and evolving societal attitudes prompt a critical evaluation of models of palliative care. We set out to identify evidence-based models of palliative care to inform policy reform in Australia.

Method: A rapid review of electronic databases and the grey literature was undertaken over an eight week period in April-June 2012. We included policy documents and comparative studies from countries within the Organisation for Economic Co-operation and Development (OECD) published in English since 2001. Meta-analysis was planned where $>1$ study met criteria; otherwise, synthesis was narrative using methods described by Popay et al. (2006).

Results: Of 1,959 peer-reviewed articles, 23 reported systematic reviews, 9 additional RCTs and 34 non-randomised comparative studies. Variation in the content of models, contexts in which these were implemented and lack of detailed reporting meant that elements of models constituted a more meaningful unit of analysis than models themselves. Case management was the element most consistently reported in models for which comparative studies provided evidence for effectiveness. Essential attributes of population-based palliative care models identified by policy and addressed by more than one element were communication and coordination between providers (including primary care), skill enhancement, and capacity to respond rapidly to individuals' changing needs and preferences over time.

Conclusion: Models of palliative care should integrate specialist expertise with primary and community care services and enable transitions across settings, including residential aged care. The increasing complexity of care needs, services, interventions and contextual drivers warrants future research aimed at elucidating the interactions between different components and the roles played by patient, provider and health system factors. The findings of this review are limited by its rapid methodology and focus on model elements relevant to Australia's health system.
\end{abstract}

Keywords: Palliative care, Models of care, Rapid review, Case management, Home based care, Nursing homes, Specialist palliative care, Acute care, Emergency departments

\section{Background}

Access to appropriate care and support at the end of life is recognised by many as a basic human right [1]. However, ongoing changes in disease and society demand rethinking who should properly receive such care, and how, where and from whom they should receive it. The traditional focus on specialist palliative care (SPC) teams caring for people with cancer in a hospice or community setting has been expanded to include a wide range of life-

\footnotetext{
* Correspondence: tim.luckett@uts.edu.au

${ }^{1}$ Improving Palliative Care through Clinical Trials (ImPaCCT), Sydney, NSW, Australia

${ }^{2}$ University of Technology Sydney (UTS), Faculty of Health, Building 10, Level 7, 235-253 Jones St, Ultimo, NSW 2007, Australia

Full list of author information is available at the end of the article
}

limiting disease groups and care settings [2]. Changes in living and social circumstances mean that current generations can no longer expect the informal caregiving taken for granted by their forbearers, forcing people to look to formalised healthcare and social services. At the same time, individualistic, consumerist attitudes mean that people demand greater choice in determining and tailoring their healthcare, including the opportunity to be cared for and die in places of preference [3].

Advances in detection and treatment mean that diseases such as cancer and HIV that previously killed people quickly are now chronic conditions that confer an increasing burden of symptoms and functional decline over many years $[4,5]$. Medical advances have also 
contributed to population ageing, facing health systems with an increasing number and proportion of frail people with multiple conditions. Despite the best of intentions, this population is often 'crisis managed' within the acute care system rather than being adequately supported in the community for as long as possible [6]. In most countries, access to healthcare varies according to socioeconomic and geographic variables, mandating efforts to decrease health disparities [7,8]. Given the increasing number and changing profile of people with life-limiting illness, it is neither feasible nor desirable that SPC services provide care for everyone; rather, these services should be reserved for patients with the most complex palliative care needs [9]. A population approach to planning is therefore required that takes a 'birds-eye view' across the health system to inform the development of models of palliative care that integrate SPC with other services according to need $[10,11]$.

The current study set out to inform Australian palliative care policy reform by identifying and synthesising:

1) recommendations for population based palliative care from international policy, and

2) the evidence for improvements on patient, family and health system outcomes available for different population-based models of palliative care from studies of any design comparing one model with another or models to usual care.

\section{Methods}

A rapid review of the palliative care literature was undertaken over an eight week period in April 2012. Rapid review methodology utilises similar processes to a full systematic review but generates a more timely synthesis of the evidence by limiting scope (e.g. search terms and inclusion criteria ) and various aspects of synthesis (e.g. data extraction and bias assessment) [12,13]. In deciding which efficiency measures to introduce, researchers undertaking rapid reviews need to carefully weigh up advantages in time/resource saving against disadvantages in the form of decreased coverage and increased risk of bias; given an appropriate balance, a rapid review can generate adequate advice for the majority of clinical and policy decision when a pre-defined methodology is followed [12]. Decisions made in the current rapid review and associated limitations are summarised in relevant parts of the Methods and Discussion. A protocol was developed and discussed prior to commencement but was not made available publically.

\section{Eligibility criteria}

Two kinds of document were deemed informative. First, we were interested to identify how various models of palliative care had been defined in the literature and which of these have been supported by evidence. We also sought international policy documents/reports with most applicability to Australia's universal health care system and federal/state structure of funding. To be included, documents of both kinds needed to come from an Organisation for Economic Co-operation and Development (OECD) country and have been made publically available in English since 2001. We limited to more recent publications to maximise relevance to contemporary populations and healthcare contexts. Documents had to be concerned with facilitating the delivery of palliative care to people with progressive life-limiting illness in any setting.

Inclusion criteria relating to palliative care were based on the World Health Organisation (WHO) definition on the basis of being the most widely used internationally [14]. Models of care were defined as those providing a framework or system for the organisation of care for people with a progressive life-threatening illness and/or their family, carers or close friends [11]. Eligible care activities included those consistent with the aims of palliative care as defined by WHO (e.g. advance care planning and self-management) as well as meeting the care needs of the patient population (e.g. symptom management and caregiver support). In accordance with the WHO definition, inclusion criteria did not relate to the degree of training and/or experience of those providing care, but rather the nature of care provided. Indeed, as indicated in the Introduction, we were especially interested to identify evidence-based models of care involving generalist or primary palliative care providers as well as specialist services.

Studies were considered eligible for inclusion if they provided data on effectiveness and/or cost-effectiveness based on comparison either between two alternative models of palliative care or between a model of palliative care and usual care. Usual care was assumed to include routine community and hospital services other than SPC models (including private). Comparisons could be concurrent or historical. Studies providing level 1 and 2 evidence (systematic reviews and randomised controlled trials [RCTs]) were prioritised, with studies using other, less rigorous designs (e.g. multiple time series) being treated as secondary sources of information [15].

We were also interested to see which models of palliative care had been recommended by current international policy. Policy document were defined as any publically available statement of position, standards or recommendations officially put forward by a government. Eligible document types included reports by health services and peak bodies as well as peer-reviewed journal articles and books/book sections.

\section{Information sources \\ Electronic searches}

We searched Medline, AMED, CINAHL, the Cochrane Database of Systematic Reviews, Health Technology 
Assessment Database and CENTRAL from their earliest records. We also searched the grey literature via internet search engines (Google and Google Scholar), the online Australian palliative care knowledge network, CareSearch, and other relevant online clearinghouses (e.g. Americans for Better Care of the Dying). Deep web searching using Mednar was considered useful for the targeting of scientific material unavailable to search engines like Google [16]. Documents listed in CareSearch's Review Collection relating to "Service/ Systems Issues" (http://www.caresearch.com.au/caresearch/tabid/501/Default.aspx) were also reviewed for inclusion.

\section{Other sources}

The reference lists of all included reviews were searched manually for further relevant articles.

\section{Search terms}

Searches for literature reporting on palliative care were conducted simultaneously with those aimed at meeting secondary aims of identifying service planning tools and research on the palliative care needs of Australians (not reported in this paper). Database searches used Medical Subject Headings (MeSH) terms or equivalent as well as keywords relating to palliative and end of life care + service models (see Table 1 for an example). Search terms were based on those for PubMed developed by CareSearch.

\section{Study selection}

Articles returned from searches of electronic databases were imported into Endnote (version X4) and coded by a single researcher against inclusion criteria for evaluative studies using a standardised proforma.

\section{Data collection process and data items}

Given the rapid nature of our review, we extracted detailed data only from those original studies not contributing to the findings of an included systematic review and data extraction was undertaken by one researcher only. Data on each model of palliative care were extracted using an electronic proforma according to a recently published disease management taxonomy which considered: patient population, intervention recipient; intervention content, delivery personnel, method of communication, intensity and complexity, environment and clinical outcomes [17]. Variables relating to study design, comparator, outcomes and findings were also extracted. Study authors were contacted via email to ask for more information as required.

\section{Assessment of bias}

Systematic reviews were quality rated by a single reviewer using the AMSTAR checklist [18]. Any RCTs we identified that were not included in one or more systematic reviews were rated for quality by a single reviewer using criteria set by the US Agency for Healthcare Research and Quality (AHRQ) [19].

\section{Synthesis}

Models of care were classified according to definitions provided by a range of sources identified by Medline and Google searches; wherever possible, definitions were taken from Australian sources to ensure relevance to the Australian healthcare system [20-33]. Classification was carried out by one reviewer, seeking input from the team as necessary where classification was not straightforward. Meta-analysis was planned where two or more studies evaluating models of care met criteria set out in the Cochrane Handbook of Systematic Reviews [19]. Where meta-analysis was not possible, synthesis took a narrative approach using techniques described by Popay and colleagues, namely: tabulation, textual descriptions, grouping and clustering, transformation of data to construct a common rubric, vote counting, and translation of data through thematic and content analysis [34-36]. Initial synthesis was undertaken by one author, with

Table 1 Medline search terms used to identify relevant articles on palliative care models, service planning tools and palliative care needs of Australians in searches conducted on $4^{\text {th }}$ April 2012

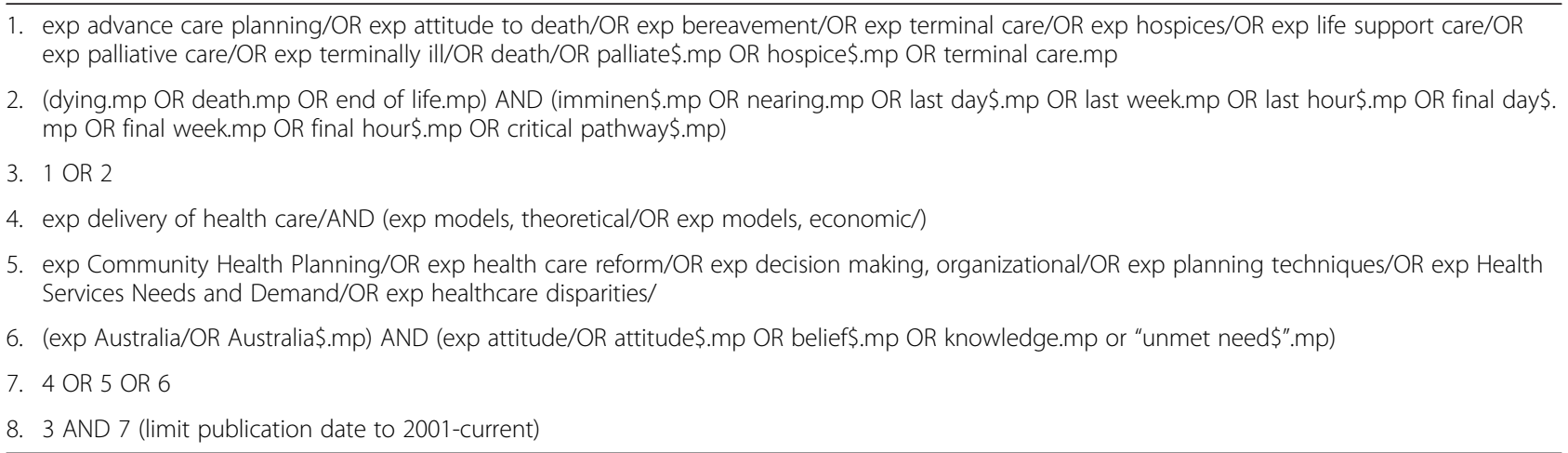


each allocated to consider findings in a particular settings (community, hospital, aged care, paediatric and regional/rural). Iterative discussion was used to distil models and elements thereof. In the absence of studies directly comparing different models of palliative care, inference was made from results comparing models with usual care as to which had most evidence for efficacy and cost-effectiveness. No formal methods were used to examine bias across studies.

\section{Results}

Table 2 includes definitions of models of palliative care identified in the literature.
A total of 1,959 articles returned from electronic databases were screened for inclusion as evaluative studies, of which 23 reported systematic reviews, 9 RCTs and 34 non-randomised comparative studies. Systematic reviews included an average of 18 studies (range 2-43) and varied as to whether they defined their focus by setting (day care [41,42], hospital [43], hospice [44], community [45-49], aged care [50], across settings [51-56]), patient group (transitioning to adult [57], HIV/AIDS [58], dementia [59]) or type of intervention (telehealth [60], caregiverfocused [61], case conferencing [62], UK Gold Standards Framework [63]). Only two of these systematic reviews limited inclusion criteria to RCTs [55,56], although all but

Table 2 Definitions of various models or components thereof for palliative care delivery found in the literature

\begin{tabular}{ll}
\hline Model/component & Definition(s) \\
\hline Case management & Case management is a collaborative process of assessment, planning, facilitation and advocacy for options and services \\
& to meet an individual's holistic needs through communication and available resources to promote quality cost effective \\
& outcomes. The definition of case management notes the focus upon the meeting of a client's health needs. Case \\
& management can be placed within a social model of health, within which improvement in health and well-being are \\
& achieved by directing efforts towards addressing the social and environmental determinants of health, in tandem with \\
biological and medical factors [31].
\end{tabular}

Consultation model

An approach to care by which specialist advice is provided on assessment and treatment of symptoms, communication about goals of care and support for complex medical decision-making, provision of practical and psychosocial support, care coordination and continuity, and bereavement services when appropriate [37]. Advice is provided without necessarily assuming primary responsibility for care, although there is negotiation of the level of palliative care involvement.

Health or clinical networks Health networks are formed when three or more health care agencies (services, organisations or health districts) formally come together to better meet the needs of patients in their service area. These agencies often include hospitals, community health centres, critical access hospitals, physician practices, mental health providers, rural health clinics and other for-profit and not-for-profit health care organizations. These health or clinical networks work to increase access to quality healthcare for local patients and streamline the cost of that care, as well [38].

Integrated care

Integrated care is a concept bringing together inputs, delivery, management and organisation of services relating to diagnosis, treatment, care, rehabilitation and health promotion. Integration is a means to improve the services in relation to access, quality, user selection and offering care [39].

Liaison model

The liaison model combines the education of patients after discharge with educational outreach and clinical support for primary care clinicians. This model may be particularly appropriate in deprived areas, where general practices vary in their capacity to manage chronic illness [40].

Managed clinical networks (MCNs)

Clinical networks are linked groups of health professionals and organisations from primary, secondary, and tertiary care working in a coordinated manner, unconstrained by existing professional and [organisational] boundaries to ensure equitable provision of high quality effective services [21]. MCNs address many of the problems that have been identified in the traditional delivery of health services, including: poor coordination and collaboration between health services; changing roles for health professionals; and the need for greater efficiencies, improved access, more equitable service provision, better use of limited resources and quality patient-centred care. More specifically, MCNs aim to develop locally delivered, quality assured care, through the managed integration of, and cooperation between, formerly separate clinical services. Their major focus is on actively involving patients in service design and building seamless services around the patient's journey to ensure the best treatment gets to the right patient, at the right time, in the most appropriate place and is delivered by the most qualified and skilled professional with the greatest resources [22].

Pop-up model

Often palliative needs in rural areas may be intermittent or needs specific. Developing a permanent infrastructure would not be appropriate in these circumstances. Looking at available local resources and gaps would provide a basis for developing a 'pop-up' palliative service model that optimises how local resources and services can be used to respond to a specific palliative need [24].

Shared care model A review [28] suggests that three definitions of shared care have been offered:

1. An approach to care which uses the skills and knowledge of a range of health professionals who share joint responsibility in relation to an individual's care. This also implies monitoring and exchanging patient data and sharing skills and knowledge between disciplines.

2. A narrower approach concerned with joint participation of general practitioners and specialists in the planned delivery of care for patients with a chronic condition, informed by an enhanced information exchange, over and above the routine discharge and referral letters.

3. Especially in mental health, shared care can be divided into systematic cooperation about how systems agree to work together and operational cooperation at local levels between different groups of clinicians. 
three included RCTs alongside other designs. In total, the reviews included 126 RCTs, 29 of which were included in more than one review. Of the $9 \mathrm{RCTs}$ we identified that had not been included in a review, three tested models using case management [64-67] and five SPC consultation [68-72].

See Figure 1 for a flowchart of inclusion/exclusion of peer-reviewed articles and Tables 3 and 4 for details of systematic reviews and RCTs respectively.

In keeping with international policy, this review found a high level of interest in addressing the palliative care needs of populations beyond people with cancer to those with illnesses such as chronic heart failure [74], endstage kidney disease [75,76], chronic obstructive pulmonary disease [77] and dementia [78]. Research has highlighted the importance of better identifying the palliative phase of these conditions in order to appropriately time advance care planning, access to symptom management and provision of support to patients and their families. Many studies included patients with a range of diagnoses and did not distinguish care or effectiveness by disease group.

Variation in the content of models, contexts in which these were implemented and lack of detailed reporting meant that no two studies met the requirements for meta-analysis that had not previously been reported in a published review. Heterogeneity in the ways models were configured and described led to a focus on the attributes of effective palliative care and service elements effective at delivering these as the most meaningful unit of analysis, rather than models of care per se.

\section{Attributes of effective palliative care}

Table 5 contains a summary of the attributes of palliative care provision recommended by English-language national policies from OECD countries.

Our review of research evidence found that few studies have been conducted across care settings, with most focusing on the provision of palliative care either in the community, acute care or aged care settings.

\section{Attributes of home-based models of palliative care}

Most commonly, models of palliative care have been aimed at supporting home-based end of life care, optimising use of SPC expertise, avoiding futile treatments and providing support for family-care givers and community health professionals $[44-49,51-53,55,56,58,61]$. The most important characteristics of home-based models of care have been documented as those that support communication and coordination, engage and enable skill enhancement both for the primary palliative care team (including general practitioners [GPs]) and informal caregivers/ patients, and clarify goals of care through advance care planning.

\section{Attributes of acute care models of palliative care}

Models of palliative care adopted in the acute care sector largely consist of specialist consultative services, in-patient

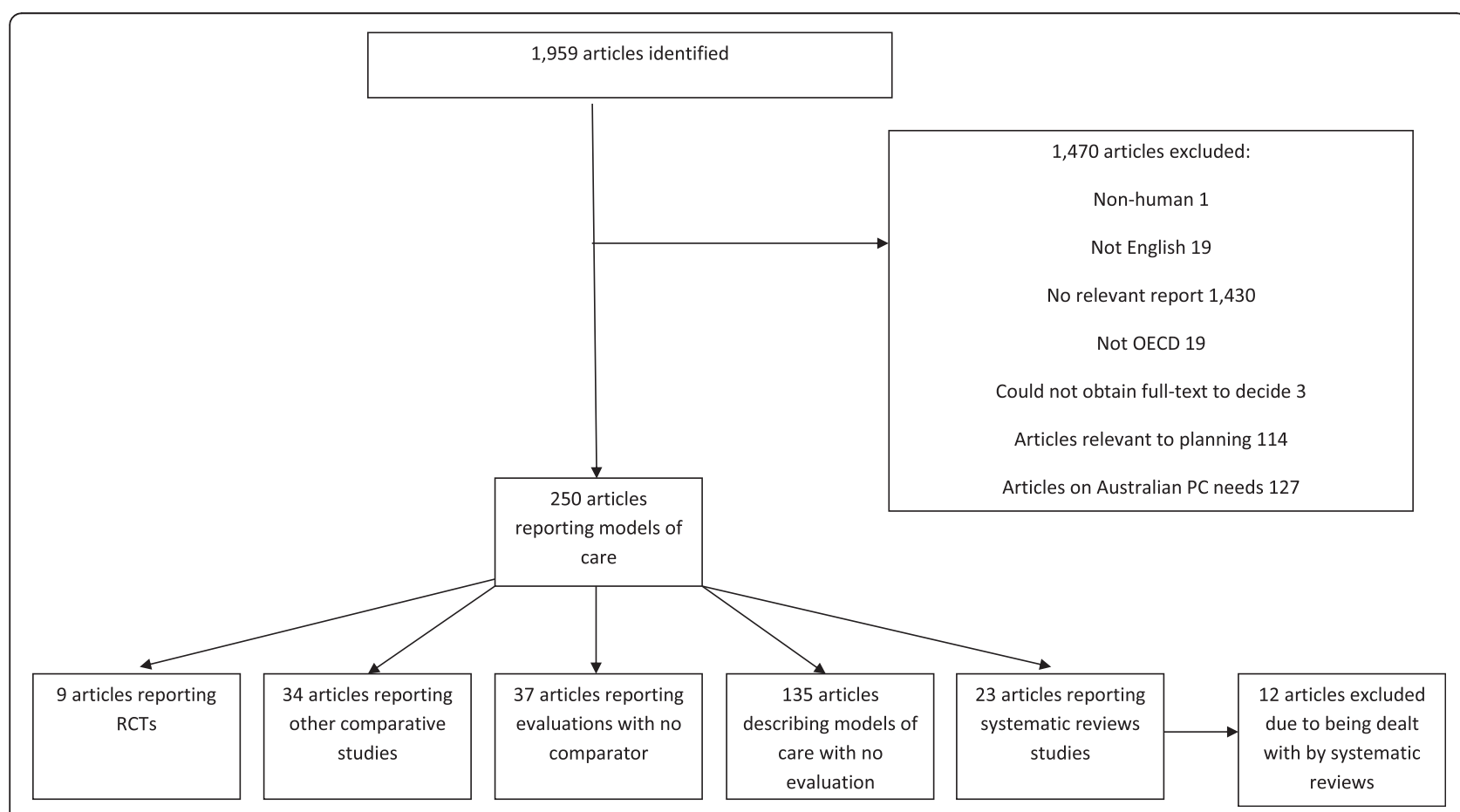

Figure 1 Flowchart for inclusion of articles reporting evaluative studies identified through searches of electronic databases. 
Table 3 Systematic reviews evaluating the efficacy of palliative models of care

\begin{tabular}{|c|c|c|c|c|c|c|c|c|}
\hline Review & Review question & Studies & Participants & Setting & Interventions & Quality * & Synthesis & Summary of results \\
\hline \multirow[t]{3}{*}{ [44] } & \multirow{3}{*}{$\begin{array}{l}\text { To identify the current } \\
\text { evidence on (1) the } \\
\text { effectiveness, including cost- } \\
\text { effectiveness, of hospices, and } \\
\text { hospice care in a patient's } \\
\text { home and in nursing homes } \\
\text { and (2) the experiences of } \\
\text { those who use and of those } \\
\text { who provide such services }\end{array}$} & $\begin{array}{l}\text { Search date: } \\
\text { 2003-2009 }\end{array}$ & \multirow[t]{3}{*}{$\begin{array}{l}\text { People dying from any } \\
\text { LLI or their family }\end{array}$} & \multirow{3}{*}{$\begin{array}{l}\text { Inpatient, } \\
\text { RAC, } \\
\text { community }\end{array}$} & \multirow{3}{*}{$\begin{array}{l}\text { EOL care service provided by } \\
\text { multidisciplinary team not part } \\
\text { of general healthcare }\end{array}$} & \multirow[t]{3}{*}{ Medium } & \multirow[t]{3}{*}{ Narrative } & \multirow{3}{*}{$\begin{array}{l}\text { Hospice services are highly } \\
\text { valued by patients and their } \\
\text { families, reduce general health } \\
\text { service use and costs, and } \\
\text { increase the likelihood of } \\
\text { effective pain management } \\
\text { and of death not occurring in } \\
\text { hospital }\end{array}$} \\
\hline & & $\begin{array}{l}\text { Designs: comparative } \\
\text { and qualitative studies }\end{array}$ & & & & & & \\
\hline & & $\begin{array}{l}\text { Number of studies: } 18 \\
\text { comparative, } 4 \\
\text { qualitative }\end{array}$ & & & & & & \\
\hline \multirow[t]{3}{*}{ [41] } & \multirow{3}{*}{$\begin{array}{l}\text { To inform future practice, } \\
\text { research and policy in specialist } \\
\text { palliative day-care by systemat- } \\
\text { ically reviewing the evidence } \\
\text { for how the structure and } \\
\text { process of this form of care re- } \\
\text { late to outcomes for adults } \\
\text { with cancer }\end{array}$} & $\begin{array}{l}\text { Search date: } \\
\text { 1872-2003 }\end{array}$ & \multirow[t]{3}{*}{ Patients with cancer } & \multirow[t]{3}{*}{ Day care } & \multirow[t]{3}{*}{ Palliative day care } & \multirow[t]{3}{*}{ Low } & \multirow[t]{3}{*}{ Narrative } & \multirow{3}{*}{$\begin{array}{l}\text { There is evidence for high } \\
\text { satisfaction among patients } \\
\text { selected into day-care, but not } \\
\text { yet sufficient to judge whether } \\
\text { this improves symptom control } \\
\text { or QOL. }\end{array}$} \\
\hline & & $\begin{array}{l}\text { Designs: Any, } \\
\text { qualitative or } \\
\text { quantitative }\end{array}$ & & & & & & \\
\hline & & Number of studies: 12 & & & & & & \\
\hline \multirow[t]{3}{*}{ [57] } & \multirow{3}{*}{$\begin{array}{l}\text { To evaluate the evidence on } \\
\text { the transition process from } \\
\text { child to adult services for } \\
\text { young people with palliative } \\
\text { care needs }\end{array}$} & $\begin{array}{l}\text { Search date: } \\
\text { 1990-2008 }\end{array}$ & \multirow[t]{3}{*}{$\begin{array}{l}\text { Children and young } \\
\text { people with LLI }\end{array}$} & \multirow{3}{*}{$\begin{array}{l}\text { Transition } \\
\text { from } \\
\text { paediatric to } \\
\text { adult } \\
\text { services, any } \\
\text { setting }\end{array}$} & \multirow[t]{3}{*}{$\begin{array}{l}\text { Interventions aimed at easing } \\
\text { transition }\end{array}$} & \multirow[t]{3}{*}{ Medium } & \multirow[t]{3}{*}{ Narrative } & \multirow{3}{*}{$\begin{array}{l}\text { Post-transition patients with } \\
\text { cystic fibrosis (and in one } \\
\text { study) parents described } \\
\text { transition positively }\end{array}$} \\
\hline & & Designs: any & & & & & & \\
\hline & & $\begin{array}{l}\text { Number of studies: } \\
\text { 92, of which only } 2 \\
\text { were evaluative }\end{array}$ & & & & & & \\
\hline \multirow[t]{3}{*}{ [45] } & \multirow{3}{*}{$\begin{array}{l}\text { To identify the models of inter- } \\
\text { professional working that pro- } \\
\text { vide the strongest evidence } \\
\text { base for practice with commu- } \\
\text { nity dwelling older people }\end{array}$} & $\begin{array}{l}\text { Search date: } \\
\text { 1990:2010 }\end{array}$ & \multirow[t]{3}{*}{ Older (age 65+) people } & \multirow[t]{3}{*}{ Community } & \multirow{3}{*}{$\begin{array}{l}\text { Inter-professional case } \\
\text { management, collaboration or } \\
\text { integrated team models }\end{array}$} & \multirow[t]{3}{*}{ Medium } & \multirow[t]{3}{*}{ Narrative } & \multirow{3}{*}{$\begin{array}{l}\text { Weak evidence of effectiveness } \\
\text { and cost-effectiveness, al- } \\
\text { though well-integrated and } \\
\text { shared care models improved } \\
\text { processes of care and have the } \\
\text { potential to reduce hospital or } \\
\text { nursing/care home use. }\end{array}$} \\
\hline & & Designs: RCTs & & & & & & \\
\hline & & Number of studies: 41 & & & & & & \\
\hline \multirow[t]{3}{*}{ [51] } & \multirow{3}{*}{$\begin{array}{l}\text { To assess whether there was } \\
\text { an effect of palliative care } \\
\text { teams }\end{array}$} & $\begin{array}{l}\text { Search date: not } \\
\text { given }\end{array}$ & \multirow{3}{*}{$\begin{array}{l}\text { Patients receiving } \\
\text { palliative care and their } \\
\text { families }\end{array}$} & \multirow[t]{3}{*}{$\begin{array}{l}\text { Inpatient or } \\
\text { community }\end{array}$} & \multirow{3}{*}{$\begin{array}{l}\text { Multi-disciplinary teams } \\
\text { including staff trained to some } \\
\text { extent in palliative care }\end{array}$} & Medium & $\begin{array}{l}\text { Narrative and } \\
\text { meta-analysis }\end{array}$ & $\begin{array}{l}\text { Most evidence is available for } \\
\text { home care services (improved }\end{array}$ \\
\hline & & Designs: not defined & & & & & $\begin{array}{l}\text { using effect } \\
\text { sizes weighted }\end{array}$ & $\begin{array}{l}\text { satisfaction and pain and } \\
\text { symptom control with lower }\end{array}$ \\
\hline & & Number of studies: 43 & & & & & $\begin{array}{l}\text { by the square } \\
\text { root of sample } \\
\text { sizes }\end{array}$ & $\begin{array}{l}\text { costs), with a smaller number } \\
\text { of studies of inpatient hospice } \\
\text { or palliative care (similar or } \\
\text { greater satisfaction, particularly } \\
\text { for carers and similar or } \\
\text { improved symptom control, } \\
\text { quality of life equivocal) and a } \\
\text { small number of poor quality } \\
\text { studies considering hospital } \\
\text { support, although it does } \\
\text { seem that these services } \\
\text { reduce time in hospital. }\end{array}$ \\
\hline
\end{tabular}


Table 3 Systematic reviews evaluating the efficacy of palliative models of care (Continued)

[52] To identify studies that

compare specialised palliative

core models betwe palliative

assessing their effectiveness or

cost-effectiveness

2003-2006

Designs: Comparative

Number of studies: 4

[50]

To determine effectiveness of Search date: to Feb multi-component palliative care 2010

service delivery interventions

for residents of care homes for older people.

Designs: Comparative

Number of studies: 3

Terminally ill patients

Inpatient,
community

Four hospice-based models (large free-standing hospice, based hospice), one palliative care unit based at a general hospital and two models of referring specialists at hospital (a

full service and a service lim-

ited to telephonic support to

the staff caring the patient)

Elderly people in aged RAC care

Designs: Any

evaluative

Number of studies: 6

To update 2003 review to determine the effectiveness of subsequently published

intervention studies targeting

informal caregivers needs in

cancer/advanced disease

\section{Search date:}

2001-2010

Designs: Any

evaluative

Number of studies: 33
Family members or carers of people with cancer or other advanced disease

Family members or carers of people with cancer or other advanced disease
Community

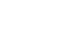

ar

dyads, Palliative care/hospice

training interventions, Respite

interventions, Group

interventions, Physical

interventions

Patients with HIV

requiring symptom

control, psychosocial hospice, community, hospital-based hospice, hom
Multi-component palliative care in RAC, including referra to external services or staff training interventions, Information and

Medium Narrative

No differences were found in control of symptoms, QOL, emotional support or

satisfaction between a broad service provided by a team of referring specialists at hospital and telephonic support between specialised PCT and the staff caring for the patient. No differences in effectiveness was found between hospitalwas found between hospitabased hospice.

One study reported higher satisfaction with care satisfaction wh care and the other found lower observed discomfort in residents with end-stage dementia. Two studies reported higher referral to hospice services in their intervention group, one found fewer hospital admissions and days in hospital, the other found an increase in do-notresuscitate orders and documented advance care plan discussions.

The current evidence contributes more to understanding feasibility and acceptability than to effectiveness.

Medium Narrative

Of 6 studies evaluating palliative care/hospice interventions, one pre/post study found reduced family anxiety about caring at home but increased wakening and poorer physical health, one cross-sectional survey found high satisfaction; the others found no effect. The one study evaluating respite found caregivers to report satisfaction after implementation.

Inpatient, Multidisciplinary advice and Medium Narrative 
Table 3 Systematic reviews evaluating the efficacy of palliative models of care (Continued)

\begin{tabular}{|c|c|c|c|c|c|c|c|c|}
\hline & $\begin{array}{l}\text { in improving patient outcomes } \\
\text { in HIV/AIDS }\end{array}$ & $\begin{array}{l}\text { Comparative Number } \\
\text { of studies: } 22\end{array}$ & $\begin{array}{l}\text { support or terminal } \\
\text { care }\end{array}$ & $\begin{array}{l}\text { long-term } \\
\text { care }\end{array}$ & $\begin{array}{l}\text { domestic support, care } \\
\text { monitoring and planning, }\end{array}$ & & & $\begin{array}{l}\text { outcomes in the domains of } \\
\text { pain and symptom control, } \\
\text { anxiety, insight, and spiritual } \\
\text { wellbeing. }\end{array}$ \\
\hline \multirow[t]{3}{*}{ [43] } & \multirow{3}{*}{$\begin{array}{l}\text { To determine whether hospital- } \\
\text { based palliative care teams im- } \\
\text { prove the process or outcomes } \\
\text { of care for patients and families } \\
\text { at the end of life }\end{array}$} & $\begin{array}{l}\text { Search date: } \\
\text { 1977-1999 }\end{array}$ & \multirow{3}{*}{$\begin{array}{l}\text { Patients with a } \\
\text { progressive life- } \\
\text { threatening illness, and } \\
\text { their family, carers, or } \\
\text { close friends. }\end{array}$} & \multirow[t]{3}{*}{ Hospital } & \multirow{3}{*}{$\begin{array}{l}\text { Palliative care teams working } \\
\text { in hospitals, defined as two or } \\
\text { more healthcare workers, at } \\
\text { least one of whom had } \\
\text { specialist training or worked } \\
\text { principally in palliative care. } \\
\text { Included interventions with a } \\
\text { hospital/support team } \\
\text { component within a broader } \\
\text { intervention }\end{array}$} & \multirow[t]{3}{*}{ Good } & \multirow{3}{*}{$\begin{array}{l}\text { Narrative and } \\
\text { meta-analysis } \\
\text { using effect } \\
\text { sizes }\end{array}$} & \multirow{3}{*}{$\begin{array}{l}\text { All studies except one } \\
\text { indicated a small positive } \\
\text { effect of the hospital team, } \\
\text { including improved symptoms, } \\
\text { fewer hospital days and better } \\
\text { satisfaction, as well as } \\
\text { improvements on process } \\
\text { measures such as increased } \\
\text { referrals, change in prescribing } \\
\text { practices. }\end{array}$} \\
\hline & & Designs: Comparative & & & & & & \\
\hline & & Number of studies: 13 & & & & & & \\
\hline \multirow[t]{4}{*}{ [53] } & \multirow{4}{*}{$\begin{array}{l}\text { To determine whether } \\
\text { specialist palliative care teams } \\
\text { achieve their aims and improve } \\
\text { outcomes for patients with } \\
\text { advanced cancer and their } \\
\text { caregivers, in terms of } \\
\text { improving symptoms and } \\
\text { quality of life and/or reducing } \\
\text { the emotional concerns of } \\
\text { family caregivers }\end{array}$} & $\begin{array}{l}\text { Search date: } \\
\text { 2000-2009 }\end{array}$ & \multirow{4}{*}{$\begin{array}{l}\text { Patients with advanced } \\
\text { cancer and their } \\
\text { caregivers }\end{array}$} & \multirow{4}{*}{$\begin{array}{l}\text { Inpatient, } \\
\text { community, } \\
\text { outpatient, } \\
\text { day care }\end{array}$} & \multirow{4}{*}{$\begin{array}{l}\text { Specialist palliative care } \\
\text { offered by professionals } \\
\text { specifically trained in palliative } \\
\text { and hospice care }\end{array}$} & \multirow[t]{4}{*}{ Medium } & \multirow[t]{4}{*}{ Narrative } & \multirow{2}{*}{$\begin{array}{l}\text { The evidence (moderate and } \\
\text { low) supports SPCTs working } \\
\text { in home, hospitals, and } \\
\text { inpatient units as a means to } \\
\text { improve outcomes for cancer } \\
\text { patients, such as pain, } \\
\text { symptom control, and } \\
\text { satisfaction, and in improving } \\
\text { care more widely, including } \\
\text { reducing hospital admissions. } \\
\text { The benefit is demonstrated } \\
\text { quantitatively. }\end{array}$} \\
\hline & & $\begin{array}{l}\text { Designs: } \\
\text { ComparativeNumber } \\
\text { of studies: } 40\end{array}$ & & & & & & \\
\hline & & & & & & & & $\begin{array}{l}\text { Studies indicated either benefit } \\
\text { in favour of a palliative care } \\
\text { team or no difference. Some } \\
\text { studies suggested lower costs. }\end{array}$ \\
\hline & & & & & & & & $\begin{array}{l}\text { Quality of life, when measured, } \\
\text { less often was different } \\
\text { between groups and tended } \\
\text { to deteriorate over time. }\end{array}$ \\
\hline \multirow[t]{3}{*}{ [60] } & \multirow{3}{*}{$\begin{array}{l}\text { To explore the use of } \\
\text { telehealth in relation to } \\
\text { palliative care in the UK }\end{array}$} & $\begin{array}{l}\text { Search date: } \\
\text { 1999-2011 }\end{array}$ & \multirow{3}{*}{$\begin{array}{l}\text { Adults, relatives, or } \\
\text { carers with palliative } \\
\text { care needs or health } \\
\text { professionals in the UK }\end{array}$} & \multirow{3}{*}{$\begin{array}{l}\text { Inpatient, } \\
\text { community, } \\
\text { outpatient, } \\
\text { RAC }\end{array}$} & \multirow[t]{3}{*}{ Telehealth } & \multirow[t]{3}{*}{ Low } & \multirow[t]{3}{*}{ Narrative } & \multirow{3}{*}{$\begin{array}{l}\text { Advantages of telehealth } \\
\text { include improved access to } \\
\text { health professionals and } \\
\text { decreased time loss and costs } \\
\text { for patients, optimized time } \\
\text { use and increased productivity } \\
\text { for health professionals, and } \\
\text { improved service efficiency for } \\
\text { providers. On the negative side, } \\
\text { the service becomes } \\
\text { depersonalized for both } \\
\text { patients and clinicians, } \\
\text { confidentiality issues may arise, } \\
\text { and potential legal implications } \\
\text { for health professionals, } \\
\text { including clinical risk }\end{array}$} \\
\hline & & Designs: Any & & & & & & \\
\hline & & Number of studies: 27 & & & & & & \\
\hline
\end{tabular}


[61] To provide a comprehensive literature review and critical appraisal of intervention studies with family caregivers of loved ones on hospice

[54] To assess evidence about interventions to improve palliative and end-of-life care

Family caregivers of patients receiving

palliative care at home in the US

People with terminal illness (for example, advanced cancer) and chronic, eventually fatal illness with ambiguous prognosis (for example advanced dementia)

Number of studies: 9 SRs and 12 studies
Palliative population
Community Videophone support, emotional support, self-care/ stress reduction, massage

\section{Any}

Case management

coordinated supportive cancer care, nurse care management in-home support, interventions targeting management and informational and relational aspects of continuity management, may be a concern. Clinical staff may be required to perform additiona research tasks such as data collection, which might not be considered the main objective when they must compete with the pressures of providing a service.Nonetheless, it appears to be both feasible and practical to make greater use of telehealth initiatives in order to provide a more equitable palliative care service that is meant not to replace but to meant not to replace but to

Generally positive findings but limited by methodological weakness and mixed results.

Moderate evidence supports multidisciplinary interventions that target continuity to affect utilization outcomes. Evidence is strong for reducing readmissions in heart failure but insufficient evidence was available for other conditions. Successful interventions involved multidisciplinary teaming, addressed patient needs across settings and over time, and facilitated communication by personal and technological means.

Community Practical nursing support with or without domestic support, COI education, transition support tele-support

Meta-analysis indicated significant effect on home deaths for SPCS with home nursing versus other care; however, the only two RCTs found no effect. Symptom management or QOL was not compromised and costs were not higher in any study that measured these.

Case conferences were generally acceptable to GPS. 
Table 3 Systematic reviews evaluating the efficacy of palliative models of care (Continued)

Does case conferencing

palliative patients?
Designs: Any

evaluative

Number of studies: 20
Community,

inpatient,

RAC

GPs and other healthcare

professionals and families

To test the efficacy of a palliative care model in

patients with dementia

966-2003

Designs: Any

evaluative

Number of studies: 2

People with advanced RAC, acute dementia

hospital

Dementia Special Care Unit

(DSCU), palliative care plans

aimed at maximising comfort

and minimising invasive or

aggressive treatment

(including hospitalisation)

Adults receiving

terminal care at home

who would otherwise
Community active treatment for

continuous periods of time by
EOL care at home providing
Participant perceived benefits included: improved

communications between

participants; increased GP

knowledge about the patient's

illness; interactive discussions

with other healthcare

professionals as a result of the

face-to-face communication:

improved inter-professional re-

spect particularly as GPs often

iid not have a good idea of

the roles played by other

health providers; a learning op-

health providers; a learning op-

mechanism for de-briefing, par-

ticularly when dealing with par-

ticularly difficult patients;

reduced professional isolation

increased team building and

promotion of a team approach

to caring for terminally ill pa-

tients. Patient outcomes in-

cluded: assisting in discharge

from hospital; improved prac-

tice; reduced inappropriate

medications, including identifi-

cation of medication-related

problems; increase patient and carer awareness of services:

identification and resolution of problems; reduced primary care visits; maintenance of function and independence; increased use of services. No effect observed on quality of life or survival; effect seemed to be

limited to outcomes the care teams had direct influence on

Patients in the DSCU had

lower discomfort and fewer transfers to acute medical setting but higher mortality; the study in the acute hospital setting found no effect on length of hospital stay or reduction in painful interventions. 
Table 3 Systematic reviews evaluating the efficacy of palliative models of care (Continued)

in hospital and what effect this Designs: Comparative require hospital or has on patients' symptoms, Number of studies:4 hospice inpatient care.

costs and care givers compared

with inpatient hospital or hos-

pice care.

[42] To determine whether the provision of palliative day care

services (PDS) have a

measurable effect on

attendees' wellbeing

[63] To review the impact of the Gold Standards Framework

(GSF) since its introduction to the UK in 200

[55] To identify and analyse all published RCTs that focus on the organization of EOL care provided to persons who are terminally ill, near death, or

dying

[56] To systematically review the evidence for effectiveness of specialized palliativecare

$\begin{array}{lll}\text { Search date: 1978- } \quad \text { Patients with LLI } & \text { Day care } & \text { Holistic, individualized } \\ 2009 & \text { palliative care, including } & \text { medical and nursing care, } \\ \text { Designs: Any } & \text { allied health and } \\ \text { evaluative } & \text { complementary therapies, } \\ \text { Number of studies:35 } & \text { social support, }\end{array}$

Search date: NR-2008 People receiving EOL Designs: Any care

Number of studies:27

Search date: NR

Designs: RCTs

People who are terminally ill, nea death or dying

Number of studies:23

\section{Search date: earliest Terminally ill}

records-2007

Designs: RCTs

Number of studies: 22

Community, Multidisciplinary care and multidisciplinary healthcare

professionals

Toolkit to improve the quality, Medium Narrative coordination and organisation of EOL care

\section{Inpatient, Multidisciplinary care, staff Low} community training inpatients, support, education, caregiver outpatients support, coordination die at home. There was some evidence of increased patien satisfaction with hom patient satisfaction with home-based end of life care, and little evidence of the impact this form of care has on caregivers. No statistically significant differences were found for functional status, psychological well-being or cognitive status.

Little evidence of impact on QOL but people report that attending PDS is a valuable experience that allows them to engage with others and to be supported in a restorative environment.

Evaluation to date has focused on the GSF's impact on care processes rather than

outcomes. The GSF has proven acceptability and can influence multidisciplinary collaboration, communication, assessment and care planning

Community or home-based EOL care compares favourably with more traditional or conventionalhospital-based and episodic medical care in improving symptoms and in the opinions of patients and caregivers

Evidence was most consistent for effectiveness of SPC in improvement of family satisfaction with care (7 of 10 studies). Only 4 of 13 studie assessing QOL and 1 of 14 assessing symptoms showed a significant benefit of the intervention; however, most studies lacked statistical power. There was evidence of significant cost savings in only 1 of 7 studies that assessed this outcome 
Table 4 Randomised controlled trials (RCTs) comparing models of care to 'usual care' and reported in the peer-reviewed literature

\begin{tabular}{|c|c|c|c|c|c|c|c|c|c|c|}
\hline Ref & $\begin{array}{l}\text { Model of } \\
\text { care }\end{array}$ & $\begin{array}{l}\text { Setting/ } \\
\text { population }\end{array}$ & $\begin{array}{l}\text { Referral/ } \\
\text { access }\end{array}$ & $\begin{array}{l}\text { Delivery } \\
\text { personnel }\end{array}$ & $\begin{array}{l}\text { Communication/ } \\
\text { coordination }\end{array}$ & $\begin{array}{l}\text { Intensity/ } \\
\text { complexity }\end{array}$ & Comparator & Outcomes & Findings & Quality* \\
\hline [64] & $\begin{array}{l}\text { Case } \\
\text { management }\end{array}$ & $\begin{array}{l}\text { Community- } \\
\text { dwelling } \\
\text { 'seriously } \\
\text { chronically ill' } \\
\text { (<2 year life } \\
\text { expectancy) } \\
\text { with COPD } \\
\text { or CHF } \\
(\mathrm{N}=192)\end{array}$ & $\begin{array}{l}\text { Patients } \\
\text { receiving } \\
\text { treatment from } \\
\text { one of multiple } \\
\text { managed care } \\
\text { organizations }\end{array}$ & $\begin{array}{l}\text { Nurse case- } \\
\text { managers, } \\
\text { supported by } \\
\text { medical dir- } \\
\text { ector, social } \\
\text { worker and } \\
\text { pastoral } \\
\text { counsellor }\end{array}$ & $\begin{array}{l}\text { Primary care physician, } \\
\text { health plan case manager } \\
\text { and community agencies }\end{array}$ & NR & $\begin{array}{l}\text { Usual care, } \\
\text { including } \\
\text { telephone- } \\
\text { based med- } \\
\text { ical and } \\
\text { disease- ori- } \\
\text { ented case } \\
\text { management }\end{array}$ & $\begin{array}{l}\text { Self-management, } \\
\text { preparation for EOL, } \\
\text { symptoms, QOL, medical } \\
\text { service utilisation }\end{array}$ & $\begin{array}{l}\text { IG reported lower } \\
\text { symptom distress, greater } \\
\text { vitality, better physical } \\
\text { functioning and higher } \\
\text { self-rated health. ED util- } \\
\text { isation was equivalent } \\
\text { across groups }\end{array}$ & Poor \\
\hline$[65,66]$ & $\begin{array}{l}\text { Case } \\
\text { management }\end{array}$ & $\begin{array}{l}\text { Rural } \\
\text { community- } \\
\text { dwelling pa- } \\
\text { tients newly } \\
\text { diagnosed } \\
\text { with ad- } \\
\text { vanced can- } \\
\text { cer }(N=322)\end{array}$ & $\begin{array}{l}\text { Patients } \\
\text { identified by the } \\
\text { VA Medical } \\
\text { Centre's tumour } \\
\text { board }\end{array}$ & $\begin{array}{l}\text { PC advanced } \\
\text { practice } \\
\text { nurses, } \\
\text { supported by } \\
\text { PC physician, } \\
\text { psychologists, } \\
\text { and 'other } \\
\text { team } \\
\text { members' }\end{array}$ & $\begin{array}{l}\text { Referral to medical teams } \\
\text { and community resources } \\
\text { as required }\end{array}$ & $\begin{array}{l}4 \text { face-to- } \\
\text { face sessions } \\
\text { with } \\
\text { monthly } \\
\text { telephone } \\
\text { follow-up } \\
\text { and group } \\
\text { shared med- } \\
\text { ical } \\
\text { meetings }\end{array}$ & $\begin{array}{l}\text { Usual care at } \\
\text { VA Medical } \\
\text { Centre }\end{array}$ & $\begin{array}{l}\mathrm{QOL} \text {, symptoms, } \\
\text { depression, days in } \\
\text { hospital, ED visits }\end{array}$ & $\begin{array}{l}\text { IG higher scores for QOL } \\
\text { and mood, but did not } \\
\text { have improvements in } \\
\text { symptom intensity scores } \\
\text { or reduced days in the } \\
\text { hospital or ICU or ED } \\
\text { visits. }\end{array}$ & Good \\
\hline [68] & Consultation & $\begin{array}{l}\text { ICU } \\
\text { inpatients } \\
\text { with a } \\
\text { terminal or } \\
\text { preterminal } \\
\text { condition } \\
(\mathrm{N}=20)\end{array}$ & $\begin{array}{l}\text { Patients } \\
\text { identified by } \\
\text { intensivist } \\
\text { indicating that } \\
\text { (s)he believed } \\
\text { treatment } \\
\text { should not be } \\
\text { escalated or } \\
\text { should be } \\
\text { withdrawn }\end{array}$ & $\begin{array}{l}\text { PC physician, } \\
\text { registrar, } \\
\text { resident and } \\
\text { clinical nurse } \\
\text { consultant }\end{array}$ & None indicated & $\begin{array}{l}\text { Daily ward } \\
\text { rounds }\end{array}$ & $\begin{array}{l}\text { Usual ICU } \\
\text { care }\end{array}$ & $\begin{array}{l}\text { ICU and hospital length of } \\
\text { stay and satisfaction with } \\
\text { quality of care of families, } \\
\text { intensivists, and bedside } \\
\text { nursing staff, ICU and } \\
\text { hospital mortality, the } \\
\text { number of medical teams } \\
\text { caring or consulting for the } \\
\text { patient }\end{array}$ & $\begin{array}{l}\text { No statistically significant } \\
\text { differences }\end{array}$ & Poor \\
\hline [69] & Consultation & $\begin{array}{l}\text { Hospital } \\
\text { inpatients } \\
\text { with LLI }\end{array}$ & $\begin{array}{l}\text { Referrals } \\
\text { received from all } \\
\text { medical services } \\
\text { and inpatient } \\
\text { units }\end{array}$ & $\begin{array}{l}\text { PC physician } \\
\text { and nurse, } \\
\text { hospital social } \\
\text { worker and } \\
\text { chaplain }\end{array}$ & $\begin{array}{l}\text { Liaised with hospital } \\
\text { subspecialists, attended } \\
\text { discharge meetings, } \\
\text { electronic discharge } \\
\text { information sent to GP }\end{array}$ & NR & $\begin{array}{l}\text { Usual } \\
\text { inpatient } \\
\text { care }\end{array}$ & $\begin{array}{l}\text { Symptom control, levels of } \\
\text { emotional and spiritual } \\
\text { support, patient } \\
\text { satisfaction, total health } \\
\text { services costs, survival, } \\
\text { number of advance } \\
\text { directives at discharge, and } \\
\text { hospice utilisation }\end{array}$ & $\begin{array}{l}\text { IG had fewer ICU } \\
\text { admissions, lower 6- } \\
\text { month net cost savings, } \\
\text { and longer median hos- } \\
\text { pice stays. There were no } \\
\text { differences in survival or } \\
\text { symptom control. }\end{array}$ & Good \\
\hline [67] & $\begin{array}{l}\text { Case } \\
\text { management }\end{array}$ & $\begin{array}{l}\text { Oncology } \\
\text { inpatients } \\
\text { and } \\
\text { outpatients } \\
\text { referred to } \\
\mathrm{PC} \text { service } \\
(\mathrm{N}=159) \text { and } \\
\text { their } \\
\text { caregivers }\end{array}$ & $\begin{array}{l}\text { Referred by } \\
\text { oncology } \\
\text { inpatient or } \\
\text { outpatient } \\
\text { services }\end{array}$ & $\begin{array}{l}\text { SPC service } \\
\text { NOS, GP }\end{array}$ & $\begin{array}{l}\text { Follow-up communication } \\
\text { in both arms via faxed or } \\
\text { posted letters, and } \\
\text { telephone communication } \\
\text { between family physician } \\
\text { and specialist, or } \\
\text { domiciliary nurses present } \\
\text { at specialist team meetings } \\
\text { acting as an intermediary }\end{array}$ & $\begin{array}{l}\text { Single case } \\
\text { conference } \\
\text { via } \\
\text { telephone } \\
\text { and follow- } \\
\text { up as } \\
\text { required }\end{array}$ & $\begin{array}{l}\text { Usual } \\
\text { oncology } \\
\text { inpatient or } \\
\text { outpatient } \\
\text { care }\end{array}$ & $\mathrm{QOL}$, caregiver burden & $\begin{array}{l}\text { No significant differences } \\
\text { in magnitude of change } \\
\text { in QOL from baseline but } \\
\text { IG showed better } \\
\text { maintenance of some } \\
\text { physical and mental } \\
\text { health measures of QoL in } \\
\text { the } 35 \text { days before death }\end{array}$ & Poor \\
\hline
\end{tabular}


Table 4 Randomised controlled trials (RCTs) comparing models of care to 'usual care' and reported in the peer-reviewed literature (Continued)

\begin{tabular}{|c|c|c|c|c|c|c|c|c|c|c|}
\hline$[70]$ & Consultation & $\begin{array}{l}\text { Outpatients } \\
\text { with New } \\
\text { York Heart } \\
\text { Association } \\
\text { functional } \\
\text { classes III and } \\
\text { IV CHF } \\
(\mathrm{N}=13)\end{array}$ & NR & SPC NOS & NR & $\begin{array}{l}\text { Initial } \\
\text { consultation } \\
+ \text { monthly } \\
\text { for } 5 \text { months }\end{array}$ & $\begin{array}{l}\text { Usual } \\
\text { cardiology } \\
\text { care }\end{array}$ & $\begin{array}{l}\text { Anxiety, depression and } \\
\mathrm{QOL}\end{array}$ & $\begin{array}{l}\text { Low recruitment and } \\
\text { attrition precluded } \\
\text { analysis }\end{array}$ & Poor \\
\hline [71] & Consultation & $\begin{array}{l}\text { Acute care } \\
\text { inpatients } \\
\text { with } \\
\text { advanced } \\
\text { dementia } \\
(\mathrm{N}=32) \text { and } \\
\text { their } \\
\text { caregivers }\end{array}$ & $\begin{array}{l}\text { Recruited from } \\
\text { acute medical } \\
\text { wards }\end{array}$ & SPC NOS & $\begin{array}{l}\text { Copies of ACPs were } \\
\text { placed in the medical } \\
\text { notes and sent to GPs and } \\
\text { RAC (where relevant) }\end{array}$ & $\begin{array}{l}\text { Up to } 4 \\
\text { consultations }\end{array}$ & $\begin{array}{l}\text { Usual } \\
\text { inpatient } \\
\text { care }\end{array}$ & $\begin{array}{l}\text { Caregiver distress, decision } \\
\text { satisfaction, QOL and (if } \\
\text { the patient died) } \\
\text { satisfaction with EOL care }\end{array}$ & $\begin{array}{l}\text { Attrition precluded } \\
\text { analysis }\end{array}$ & Poor \\
\hline [72] & Consultation & $\begin{array}{l}\text { Oncology } \\
\text { outpatients } \\
\text { with newly } \\
\text { diagnosed } \\
\text { metastatic } \\
\text { non-small- } \\
\text { cell lung } \\
\text { cancer } \\
(\mathrm{N}=151)\end{array}$ & $\begin{array}{l}\text { Recruited from } \\
\text { oncology } \\
\text { outpatients }\end{array}$ & $\begin{array}{l}\text { PC palliative } \\
\text { care } \\
\text { physicians } \\
\text { and } \\
\text { advanced- } \\
\text { practice } \\
\text { nurses }\end{array}$ & Care coordination NOS & $\begin{array}{l}\text { Average } \\
\text { number of } 4 \\
\text { SPC visits }\end{array}$ & $\begin{array}{l}\text { Usual } \\
\text { oncologic } \\
\text { care }\end{array}$ & $\begin{array}{l}\text { Anxiety, depression, } \mathrm{QOL}, \\
\text { survival, health service use }\end{array}$ & $\begin{array}{l}\text { IG had higher QOL, lower } \\
\text { depression and longer } \\
\text { survival despite less } \\
\text { aggressive EOL care }\end{array}$ & Good \\
\hline
\end{tabular}


palliative units/beds or nurse practitioner models [82,83]. In a landmark study from the US, SPC consultation was found to improve not only quality of life but also surival for patients with advanced lung cancer [72]. Specialist consultative service models have tended to focus on: 1) discussions about prognosis and goals of care; 2) pursuing documentation of advance directives; 3) discussion about foregoing specific treatments and/or diagnostic interventions; 4) family and patient support; 5) discharge planning; and 6) symptom management [84]. Consultative services provided by hospital palliative care teams have been shown to improve symptom control and quality of life, alleviate emotional burden and improve caregiver and patient satisfaction $[85,86]$. In addition they have resulted in hospital cost saving $[87,88]$. Currently, SPC in the US acute care setting is more likely to be available in larger hospitals, academic medical centres, not-for-profit hospitals, and Veterans Affairs (VA) hospitals compared to others [89]. Dedicated palliative care units have been established but struggle to meet increasing demands.

The increasing pressure on emergency departments and recognition of their role in end-of-life care highlight the dearth of community based services and failure of advance care planning [90-92]. Commonly, emergency presentations result from inadequate symptom control in the community and/or absence of adequate care givers [93-95]. In some countries, financial issues also act as an incentive for patients to access treatment through the emergency department in preference to other services [96]. A particular issue is the uncertainty that emergency department health professionals face when forced to make decisions in the absence of a detailed case history and advance care plans [92]. Studies have identified the capacity of coordinated models of care to decrease unnecessary emergency department usage and inappropriate admission, especially to intensive care $[97,98]$.

\section{Attributes of residential aged care models of palliative care} A setting that has proven especially challenging to improvements in quality of end of life care is residential aged care [99]. Older people in aged care are less likely to be referred to SPC services for consultation or ongoing management and more likely to have poor symptom control, unnecessary hospitalisations, sub-optimal communication, inadequate advance care planning and families who are dissatisfied with end of life care [50]. A recent Cochrane Review [50] examining multi-component palliative care interventions for older people in nursing homes identified three studies [100-102] graded as 'poor quality' that provided weak evidence for the following model of palliative care elements: i) communication - identifying residents who would benefit from an SPC referral and negotiating this with their doctor and family [100]; ii) development of palliative care leadership teams, technical assistance meetings for team members, education in palliative care for all staff, plus feedback on performance [102]; and iii) targeted symptom control strategies to improve discomfort [101]. Systematic reviews on the efficacy of palliative care in dementia have identified a very limited evidence-base with which to develop appropriate interventions or services [54,59].

\section{Attributes of care required during transitions}

Models of care are faced with special challenges during transitions between care settings (community, aged care and hospital) where support is needed to avoid patients 'falling through the cracks' [103] and/or when a rapid response is required in the context of quickly changing clinical status or patient preferences for place of care (e.g. wishing to return home while still possible) [104]. As patients and caregivers may lack knowledge of what services are available and how to access them [105], navigating the transition from inpatient to community based care requires intensive effort and coordination to put management plans and caregiver support in place. The importance of supporting transitions is especially underscored in advanced dementia where, unless a care plan is in place, health professionals in acute care may lack awareness that a palliative approach is appropriate and initiate treatments inappropriately aimed at prolonging life with negative effects on quality of life [106,107]. Transitional care between paediatric and adult palliative care services is also a focal point requiring intensive support [57].

\section{Elements of effective models of palliative care}

This review identified a number of dynamic elements that have been integrated into palliative care models in a range of care settings to enable access to appropriate services, improve communication and coordination between providers, enhance palliative care skills of non-specialist and informal carers, and inrease capacity to respond rapidly to individual patient needs and preferences as these change over time.

\section{Case management}

Case management is a recurring feature of many successful models [43-45,48,49,51,53-56,58,62,64-69] that seeks to assess and meet the full range of each individual's palliative care and other needs, including those relating to activities of daily living (e.g. house-work) and social wellbeing. As a result, case management frequently requires coordination of services beyond the healthcare sector, including social services and pastoral care. Case management is informed by the principles of patient-centred care [108]; as such, patients and families themselves often play an active role in determining which services they receive. 


\section{Table 5 Attributes of models for palliative care recommended by national policy documents from OECD countries} available in English

\section{Country Attributes of palliative care service delivery recommended by national policy}

Australia [23] • Provide enhanced, coordinated support for carers, volunteers, communities of carers and carer respite

- Provide coordinated, flexible local care delivery for people at the end of life regardless of where they live and address any barriers

- Further improve the skill and confidence of the generalist workforce

- Enhance online palliative care support to ensure adequate numbers of skilled palliative care specialist providers across all disciplines

- Include end of life and palliative care competencies in all care worker training packages

- Enhance and legitimise the role of specialist consultancy services in providing direct clinical advice, education and training, advocacy for end of life issues and training places

- Record and track advance care planning within electronic health records

- Develop sustainable models of quality palliative care in the private sector

- Develop the role of the general practitioner in palliative care

- Undertake further research and ongoing monitoring of the relative cost of care

Canada [79] - Availability and access to services

- Education for healthcare providers

- Ethical, cultural and spiritual considerations

- Public education and awareness

- Support for family, caregiver and significant others

Ireland [80] - Provision of physical, psychological, social and spiritual support, with a mix of skills, delivered through a multi-professional, collaborative team approach

- Patients and families are supported and involved in management plans

- Patients are encouraged to express their preference about where they wish to be cared for and where they wish to die

- Carers and families are supported through the illness into bereavement

- The overall whole time equivalent (WTE) SPC nurse to bed ratio should not be less than 1:1

- In each day care centre, there should be a minimum of one WTE SPC nurse to every 7 daily attendees.

- There should be a minimum of one WTE specialist palliative care nurse per 150 beds in each acute general hospital

- There should be a minimum of one WTE specialist palliative care nurse in the community per 25,000 populations.

- There should be at least one WTE physiotherapist per 10 beds in the specialist palliative care inpatient unit, with a minimum of one physiotherapist in each unit

- There should be a minimum of one WTE community physiotherapist specialising in palliative care per 125,000 population. This post should be based in the specialist palliative care unit

- There should be at least one WTE occupational therapist per 10 beds in the specialist palliative care inpatient unit, with a minimum of one occupational therapist in each unit.

- There should be a minimum of one WTE community occupational therapist specialising in palliative care per 125,000 populations This post should be based in the specialist palliative care unit

- There should be at least one WTE social worker employed per 10 beds in the specialist palliative care unit, with a minimum of one social worker in each unit

- There should be a minimum of one WTE community social worker specialising in palliative care per 125,000 population. This post should be based in the specialist palliative care unit

- Specialist palliative care services in all other settings, including general hospitals and the community, should be based in or have formal links with the specialist palliative care unit

- All specialist palliative care units should provide day care facilities for patients and carers

- Appropriate transport should be provided for patients to and from the centre

- There should be one point of entry to hospital services for palliative care patients, and subsequent referrals should be speedily organised

- In Accident and Emergency, the patient's condition should be rapidly assessed, and the patient should be referred to the appropriate team without delay

- The specialist palliative care team in the community should be an inter-disciplinary consultant-led team

- The specialist palliative care team should be based in, and led by, the specialist palliative care unit in the area 


\section{Table 5 Attributes of models for palliative care recommended by national policy documents from OECD countries available in English (Continued)}

\begin{tabular}{l}
\hline - Specialist palliative care nurses should provide a seven-day service to patients in the community \\
- Arrangements should be made for the transport of patients receiving palliative care to different care settings, when required \\
• Bereavement support should begin early in the disease process, long before the death of the patient. \\
- Multidisciplinary assessment to ensure that all needs are identified early and individualised plan is established \\
- Allocate a care coordinator to each dying person \\
- Provide access to clinical care for each dying person (medical services, respite care, counselling, etc.) \\
New Zealand \\
- Provide access to support services for dying patients and their families \\
- Ensure dying people and their families have access to essential palliative care (initial and specialized palliative acre)- at least one \\
local palliative care service in each district health board \\
- Provide induction and ongoing training for volunteers in the community assisting in palliative care \\
- Provide flexible palliative care to meet varying and specific needs \\
- Inform the public about PCS.
\end{tabular}

\section{Shared care}

Whilst defintions of shared care have varied (Table 2), it has been frequently reported as an element of effective palliative care delivery, utilised by a number of different models [109]. Characteristics of shared care seem to have commonly included: an identifiable lead clinician working together with health professionals from other disciplines, a focus on communication and coordination, and a rapid needs-based response and navigational strategies.

A model of care that incorporates case management and shared care and has been recommended by policy in Australia in the absence of evaluation data is the 'pop up' model. This model was originally developed to extend palliative care to rural/remote adult services and has since been recommended for paediatric palliative care [110]. The model develops a rapid-response team around the patient and their family drawn from primary, communitybased and SPC services as required to address each client's care plan. The model relies on excellent coordination, established networks and a system of triggers for referrals, re-assessments and re-referrals to provide intensive support over brief periods. In the UK, a coordinating role for a similar model has been assigned to paediatric oncology outreach nurse specialists to support children dying from cancer $[111,112]$. The outreach nurse role is described as 'empowering the primary healthcare team through advice and direct patient care; providing an interface between primary, secondary, and tertiary care services; and coordinating services' [111] (p.4474).

\section{Specialist outreach services}

Internationally, specialist outreach services have been widely adopted to improve care outcomes for underserved populations through the establishment of: i) specialist clinics in urban primary care practices; ii) specialist clinics in rural hospitals where no specialist services exist; and iii) sub-specialist clinics in regional centres [113]. A Cochrane review examined efficacy of specialist outreach services in primary care and rural hospital settings implemented as one element of complex multifaceted interventions involving collaboration with primary care, education or other health services [113]. This review concluded that specialist outreach services can improve health outcomes, ensure delivery of more efficient and consistent evidence-based care, and reduce the use of inpatient services. The additional costs associated with the provision of specialist outreach appear to be balanced by improved health outcomes. None of the studies in the review included comparisons of palliative care specialist outreach services; their widespread use raises a need for evaluation [114].

\section{Managed clinical networks and/or health networks (clinical networks)}

Across the globe, clinical networks have been integrated into many healthcare systems as part of a wider reform agenda to ensure that underserved populations and those with poorer outcomes have better access to quality, clinically-effective health services $[115,116]$. Clinical networks facilitate the formal linking of groups of health professionals and organisations from primary, secondary and tertiary care to work in a coordinated manner, unconstrained by existing professional and organisational boundaries [117]. Many of these boundaries are driven by funding models and geographical boundaries. Although conceptually appealing, few empirical studies have been undertaken to evaluate the effectiveness of clinical networks. A literature review identified eight empirical studies, including comparative and observational designs [117]. The review concluded that clinical networks - when formally established, with governance and guidelines in place - facilitated access to care for people in underserved communities. 


\section{Integrated care}

Numerous studies identified the crucial role of integrated care [51-56]. Integration refers to coordination of disparate services centred on the needs of each individual patient and family with the aim of ensuring continuity of care. Integrated care requires that patients and families are involved in informed decision-making and goal setting. It is based on principles of advocacy and respect that provide seamless, continuous care from referral through to bereavement and across organizational boundaries. Positive effects of integrated care in paediatrics have been demonstrated not only for patient and family outcomes, but also on organisational efficiencies and staff satisfaction [57].

Integrated care is especially important when supporting adults or children in the community, the enablement of which is increasingly prioritised by policy in many countries $[118,119]$. While the role of primary care at the end of life is important everywhere, palliative care support for primary healthcare is most essential in rural and regional areas, where the burden for coordinating and providing medical care falls predominantly on general practitioners (GPs) and nursing care to community nurses [120,121]. Data suggest that in some jurisdictions, including Australia, many GPs want to be involved in palliative care delivery but have decreasing capacity to undertake visits to homes or aged care facilities due to workload, time constraints and inadequate remuneration [7,122-126]. Whilst there are no evidence-based models for palliative care in the primary healthcare setting $[127,128]$, there is emerging evidence that the UK's Gold Standards Framework (GST) has improved communication, collaboration, assessment and planning since its introduction in 2001 [63]. It should be noted, however, that the UK's National Health Service has unique drivers not readily transferrable to countries such as Australia with different healthcare funding models and multiple jurisdictions.

\section{Volunteers}

Use of volunteers may have potential where informal caregivers are lacking; however, appropriate governance models are needed. Volunteer models have been used across a range of palliative care settings but evidence of implementation and evaluation is limited [129-132].

\section{Cost-effectiveness}

Most studies that have examined cost-effectiveness of palliative care services versus usual care have found either no significant difference or palliative care to compare favourably $[44,45,48,51,53,56]$. However, there remains controversy as to appropriate methods of measuring costeffectiveness in care for the dying. The limited survival of this patient population proves a challenge for cost-utility methods; most analyses to date have focused on costs alone, with little integration of data on efficacy. Furthermore, relatively little attention has been given to costs incurred by family caregivers who may absorb costs shed by the healthcare system via community care interventions aimed at avoiding hospital admissions. No data were found comparing cost-effectiveness of different models of palliative care beyond usual care.

\section{Discussion}

Like previous systematic reviews in palliative care [133], we found few well-designed RCTs comparing models of palliative care with each another, or even with usual care. Systematic reviews have tended to include servicelevel interventions defined by setting (e.g. day care [42]) and/or the population served (e.g. people with dementia [59]) rather than by model of care. This consideration led us to redirect our synthesis away from whole models to focus on service elements consistently featured in models found to be effective. Of these elements, case management has been perhaps the most commonly supported [43-45,48,49,51,53-56,58,62,64-69], albeit usually contributing to a complex intervention alongside a number of interacting components, different in each study. These considerations limit our ability to state with confidence that positive outcomes have resulted from case management per se.

Our review also identified the role required of political drivers in leveraging health system reform. Case management demands care across jurisdictions and care settings, which is not easy to achieve in a state/federal funding structure of the kind seen in Australia. The influence of local drivers also means that some models of care have been based on geo-political boundaries that may not be readily transferrable to other regions [63,134-136].

Two new systematic reviews published since our search was conducted have provided important data on cost-effectiveness of palliative care. The value of home based palliative care has been demonstrated in a recent meta-analysis which found that receiving home palliative care doubles the odds of dying at home and reduces symptom burden, especially for patients with cancer, without having an adverse impact on caregiver grief [137]. A systematic review using narrative synthesis concluded that palliative care of all kinds was generally found to be cost-effective compared with usual care, usually statistically so [138].

\section{Limitations and areas for future research}

The rapid nature of the current review is associated with a number of methodological limitations [12,13]. Limiting the scope of our search and associated terms is likely to have resulted in relevant references having been missed and increased the risk of publication and country/language 
biases [139]. Our inclusion criteria and approach to synthesis favoured reviews over original research and relied on a somewhat 'blunt' comparison that did not control for overlap between reviews. Limitations in time and resources also required us to forego the level of documentation commonly associated with full systematic reviews. These limitations were moderated somewhat by the use of the online resource 'CareSearch' which was designed by experts specifically to identify palliative care evidence [140] and quality assessment involving experts, including the authors of key research [141]. However, the emphasis we placed on models of care relevant to the Australian healthcare system will inevitably limit applicability of findings to some other countries.

As mentioned, the current review was also limited by variations in reporting of service models that precluded comparison and accumulation of evidence for any given model. The term 'model of care' was itself used inconsistently and relatively infrequently in the literature; a Medline search using terms for 'palliative care' combined with 'model(s) of care' returned only $1 \%$ of articles returned by searching for palliative care alone. Inconsistency and incompleteness in reporting impairs not only synthesis of research but also replication of successful models in future evaluations and implementation into practice. Researchers are encouraged to follow guidance on key variables to report that would enable greater comparability and support replication and refinement of models in research and practice [142].

The literature's focus on elements rather than models raises important questions about how these elements might interact to the betterment or detriment of care quality and outcomes. The pop up model is one example of a model of care that has been recommended by policy without evidence for its effectiveness as a whole but rather an assumption that effective elements can be combined to optimise benefit [110]. Future evaluations should use factorial designs and process measures to clarify causal mechanisms between elements and identify influential contextual factors to inform ongoing development and tailoring to local needs and resources [143].

Finally, our review was limited by the problem we encountered in mapping between evidence at the outcome levels of patient (e.g. symptoms), caregiver (e.g. satisfaction), provider (e.g. knowledge of palliative care needs) and service (e.g. hospital days). A recent systematic review identified 15 patient-level domains alone, including quality of life, quality of care, symptoms and problems, performance status, psychological symptoms, decisionmaking and communication, place of death, stage of disease, mortality and survival, distress and wish to die, spirituality and personality, disease-specific outcomes, clinical features, meaning in life and needs [144]. The plethora of outcomes and associated measures is a recognised barrier to comparability between studies [145-150]. Whilst the WHO palliative care definition provides a framework for evaluating palliative care at the levels of the patient, provider and system, this has not yet been undertaken for any known model of palliative care. There is also a need for comprehensive economic evaluations that include descriptions of patient preferences as well as consideration of costs incurred by family caregivers and sub-group analyses examining the influence of disease and socio-demographic factors $[138,151]$.

\section{Conclusion}

Heterogeneity in definitions and reporting mechanisms limit the focus of conclusions from this rapid review to attributes and elements of successful palliative care services rather than whole models. Best practice palliative care should be accessible to all who need it, tailored to individual patient and family's palliative care needs in a timely manner, and extend beyond organisational and disciplinary boundaries as required via strategies that support communication and coordination. Population-based models of palliative care should therefore include elements that support case management via integration of SPC with primary and community care services, and enable transitions across settings, including residential aged care.

While palliative care models may have once been relatively homogenous, dynamic models are increasingly required to accommodate rapidly changing population demands and health system structure and drivers. Access to specialist services for rural and regional patients and carers has been identified as especially in need of targeted intervention. The current focus on medical and nursing service delivery should also be broadened to incorporate services addressing social and environmental determinants of health as required.

Increasing complexity in service configuration warrants consideration by future research of the roles played by contextual factors such as funding and policy in order to inform planning at the population level. Research should ideally test the impact of changes over time both within and between regions using standard measures of process and outcomes.

\section{Abbreviations}

GP: General practitioner; SPC: Specialist palliative care.

\section{Competing interests}

The authors declare that they have no competing interests.

\section{Authors' contributions}

All authors contributed to design and conduct of the review, synthesis and interpretation of results and reporting. All authors read and approved the final manuscript.

\section{Funding}

The research team was commissioned by the Sax Institute to undertake this rapid review for New South Wales Ministry of Health in April 2012. 


\section{Author details}

${ }^{1}$ Improving Palliative Care through Clinical Trials (ImPaCCT), Sydney, NSW, Australia. ${ }^{2}$ University of Technology Sydney (UTS), Faculty of Health, Building 10, Level 7, 235-253 Jones St, Ultimo, NSW 2007, Australia. ${ }^{3}$ South Western Sydney Clinical School, University of New South Wales (UNSW), Sydney, NSW, Australia. ${ }^{4}$ The Cunningham Centre for Palliative Care Sydney, Sacred Heart Hospice, Sydney, NSW, Australia. ${ }^{5}$ School of Nursing, The University of Notre Dame Australia, Sydney, NSW, Australia. ${ }^{6}$ HammondCare, Sydney, NSW, Australia. ${ }^{7}$ The Ingham Institute for Applied Medical Research, Sydney, NSW, Australia. ${ }^{8}$ School of Nursing, Johns Hopkins University, Baltimore, MD, USA.

Received: 17 September 2013 Accepted: 10 March 2014

Published: 26 March 2014

\section{References}

1. Ahmedzai SH, Costa A, Blengini C, Bosch A, Sanz-Ortiz J, Ventafridda V, Verhagen SC, International working group convened by the European School of O: A new international framework for palliative care. Eur J Cancer 2004, 40(15):2192-2200.

2. Watson $\mathrm{M}$, Watson $\mathrm{M}$ : Changing emphasis in end-of-life care. Br J Hosp Med (Lond) 2010, 71(1):6-7.

3. Doron I: Caring for the dying: from a "negative" to a "positive" legal right to die at home. Care Manag J 2005, 6(1):22-28.

4. Phillips JL, Currow DC: Cancer as a chronic disease. Collegian 2010, 17:47-50,

5. Deeks SG, Lewin SR, Havlir DV: The end of AIDS: HIV infection as a chronic disease. Lancet 2013, 382(9903):1525-1533.

6. Barbera L, Taylor C, Dudgeon D: Why do patients with cancer visit the emergency department near the end of life? CMAJ 2010, 182(6):563-568.

7. Walshe C, Todd C, Caress A, Chew-Graham C: Patterns of access to community palliative care services: a literature review. J Pain Symptom Manage 2009, 37(5):884-912.

8. Cohen LL: Racial/ethnic disparities in hospice care: a systematic review. J Palliat Med 2008, 11(5):763-768.

9. Quill T, Abernethy AP: Generalist plus specialist palliative care-creating a more sustainable model. N Engl J Med 2013, 368(13):1173-1175.

10. Currow DC, Nightingale EM: "A planning guide": Developing a consensus document for palliative care service provision. Med J Aust 2003, 179(6 Suppl):S23-25.

11. Davidson P, Halcomb E, Hickman L, Phillips J, Graham B: Beyond the rhetoric: what do we mean by a 'model of care'? Aust J Adv Nurs 2006, 23(3):47-55.

12. Watt A, Cameron A, Sturm L, Lathlean T, Babidge W, Blamey S, Facey K, Hailey D, Norderhaug I, Maddern G: Rapid versus full systematic reviews: validity in clinical practice? ANZ J Surg 2008, 78(11):1037-1040.

13. Ganann R, Ciliska D, Thomas H: Expediting systematic reviews: methods and implications of rapid reviews. Implement Sci 2010, 5:56.

14. WHO definition of palliative care. [http://www.who.int/cancer/palliative/ definition/en/]

15. National Heath and Medical Research Council: NHMRC levels of evidence and grades for recommendations for developers of guidelines. Canberra: NHMRC; 2009 .

16. The Deep Web: Surfacing Hidden Value. [http://www.mpi-inf.mpg.de/departments/ d5/teaching/ws01_02/proseminarliteratur/deepwebwhitepaper.pdf]

17. Krumholz HM, Currie PM, Riegel B, Phillips CO, Peterson ED, Smith R, Yancy CW, Faxon DP, American Heart Association Disease Management Taxonomy Writing G: A taxonomy for disease management: a scientific statement from the American Heart Association Disease Management Taxonomy Writing Group. Circulation 2006, 114(13):1432-1445.

18. Shea BJ, Bouter LM, Peterson J, Boers M, Andersson N, Ortiz Z, Ramsay T, Bai A, Shukla VK, Grimshaw JM: External validation of a measurement tool to assess systematic reviews (AMSTAR). PLOS ONE 2007, 2(12):e1350.

19. The Cochrane Collaboration. Cochrane Handbook for Systematic Reviews of Interventions Version 5.0.1. Edited by Higgins JPT, Green S. Chichester: John Wiley \& Sons Ltd; 2008.

20. Adams P, Hardwick J, Embree V, Sinclair S, Conn B, Bishop J: Literature Review Models of Cancer Services for Rural and Remote Communities. Cancer Institute NSW: Sydney; 2009.

21. Glossary. [http://www.canceraustralia.gov.au/node/212\#M]

22. CanNET National Support and Evaluation Service - Siggins Miller: Managed Clinical Networks - A Literature Review. Canberra: Cancer Australia; 2008
23. Commonwealth of Australia: Supporting Australians to Live Well at the End of Life National Palliative Care Strategy. Canberra: Commonwealth of Australia; 2010.

24. Currow D, Tieman J: Phase One of the National Palliative Care Research Program Summary Paper. Adelaide: Flinders University; 2005.

25. Department of Health WA: Palliative Care Model of Care. Perth: Department of Health WA; 2008.

26. Kodner DS, Spreeuwenberg C: Integrated care: meaning, logic, applications, and implications - a discussion paper. Inter J Integr Care 2002, 2(6):e12.

27. Shared care models: a high-level literature review. [http://www.cancerinstitute org.au/incite/issue-1/shared-care-models-a-high-level-literature-review]

28. Chomik TA: A Report on Shared Care (Part of the Primary Health Care Shared Care Network Development Initiative). Vancouver: Provincial Health Services Authority; 2005.

29. Maddocks I, Parker D, McLeod A, Jenkin P: Palliative care nurse practitioners in aged care facilities: Report to the Department of Human Services. Adelaide: International Institute of Hospice Studies; 1999

30. Palliative Care Australia: A guide to palliative care service development: $A$ population based approach. Canberra: Palliative Care Australia; 2005.

31. What is Case Management? [http://www.cmsa.org.au/definition.html]

32. Rural general practice - Definition. [http://www.racgp.org.au/rural/definition]

33. Tieman J, Mitchell G, Shelby-James T, Currow D, Fazekas B, O'Doherty L, Hegarty M, Eriksson L, Brown R, Reid-Orr D: Integration, Coordination and Multidisciplinary Approaches in Primary Care: A systematic investigation of the literature. Canberra: Australian Primary Health Care Research Institute; 2006.

34. Popay J, Roberts H, Sowden A, Petticrew M, Arai L, Rodgers M, Britten N, Roen K, Duffy S: Guidance on the Conduct of Narrative Synthesis in Systematic Reviews: Final report. A Product from the ESRC Methods Programme. Lancaster: University of Lancaster; 2006.

35. Arai L, Britten N, Popay J, Roberts H, Petticrew M, Rodgers M, Sowden A: Testing methodological developments in the conduct of narrative synthesis: a demonstration review of research on the implementation of smoke alarm interventions. Evid Policy 2007, 3(3):361-383.

36. Rodgers M, Petticrew M, Sowden A, Arai L, Britten N, Popay J, Roberts H: Testing methodological guidance on the conduct of narrative synthesis in systematic reviews: effectiveness of interventions to promote smoke alarm ownership and function. Evaluation 2009, 15(49). doi:10.1177/ 1356389008097871.

37. Penrod JD, Deb P, Luhrs C, Dellenbaugh C, Zhu CW, Hochman T, Maciejewski ML, Granieri E, Morrison RS: Cost and utilization outcomes of patients receiving hospital-based palliative care consultation. [Erratum appears in J Palliat Med, Dec;9(6):1509]. J Palliat Med 2006, 9(4):855-860.

38. NCHN Elects Leadership for 09-10 and Recognizes Three Health Networks. [http://www.nchn.org/news-article.php?id=57]

39. World Health Organization: Towards age-friendly primary health care. Geneva: WHO; 2004.

40. Griffiths C, Foster G, Barnes N, Eldridge S, Tate H, Begum S, Wiggins M, Dawson C, Livingstone AE, Chambers M, Coats T, Harris R, Feder G Specialist nurse intervention to reduce unscheduled asthma care in a deprived multiethnic area: the east London randomised controlled trial for high risk asthma (ELECTRA). BMJ 2004, 7432(328):144.

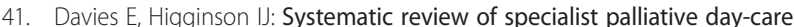
for adults with cancer. Support Care Cancer 2005, 13(8):607-627.

42. Stevens $E$, Martin CR, White CA: The outcomes of palliative care day services: a systematic review. Palliat Med 2011, 25(2):153-169.

43. Higginson IJ, Finlay I, Goodwin DM, Cook AM, Hood K, Edwards AGK, Douglas H-R, Norman CE: Do hospital-based palliative teams improve care for patients or families at the end of life? J Pain Symptom Manage 2002, 23(2):96-106.

44. Candy B, Holman A, Leurent B, Davis S, Jones L: Hospice care delivered at home, in nursing homes and in dedicated hospice facilities: A systematic review of quantitative and qualitative evidence. Int J Nurs Stud 2011, 48(1):121-133.

45. Evans C, Goodman C: End of life care for older people with dementia living in a care home. J Integr Care 2008, 16(6):15-25.

46. Harding $\mathrm{R}$, Higginson IJ: What is the best way to help caregivers in cancer and palliative care? A systematic literature review of interventions and their effectiveness. Palliat Med 2003, 17(1):63-74.

47. Harding R, List S, Epiphaniou E, Jones H: How can informal caregivers in cancer and palliative care be supported? An updated systematic 
literature review of interventions and their effectiveness. Palliat Med 2012, 26(1):7-22

48. Luckett T, Davidson PM, Lam L, Phillips J, Currow DC, Agar M: Do Community Specialist Palliative Care Services That Provide Home Nursing Increase Rates of Home Death for People with Life-Limiting Illnesses? A Systematic Review and Meta-Analysis of Comparative Studies. J Pain Symptom Manage 2013, 45(2):279-297.

49. Shepperd S, Wee B, Straus Sharon E: Hospital at Home: Home-based End of Life Care. In Cochrane Database of Systematic Reviews. Chichester: John Wiley \& Sons, Ltd; 2011

50. Hall S, Kolliakou A, Petkova H, Froggatt K, Higginson Irene J: Interventions for Improving Palliative Care for Older People Living in Nursing Care Homes. Cochrane Db Syst Rev 2011, 16(3):CD007132. doi:10.1002/14651858. CD007132.pub2

51. Finlay IG, Higginson IJ, Goodwin DM, Cook AM, Edwards AGK, Hood K, Douglas HR, Normand CE: Palliative care in hospital, hospice, at home: results from a systematic review. Ann Oncol 2002, 13(Suppl 4):257-264.

52. Garcia-Perez L, Linertova R, Martin-Olivera R, Serrano-Aguilar P, BenitezRosario MA: A systematic review of specialised palliative care for terminal patients: which model is better? Palliat Med 2009, 23(1):17-22.

53. Higginson IJ, Evans CJ: What is the evidence that palliative care teams improve outcomes for cancer patients and their families? Cancer J 2010, 16(5):423-435

54. Lorenz KA, Lynn J, Dy SM, Shugarman LR, Wilkinson A, Mularski RA, Morton SC, Hughes RG, Hilton LK, Maglione M, Rhides SL, Rolon C, Sun VC, Shekelle PG: Evidence for improving palliative care at the end of life: a systematic review. Ann Intern Med 2008, 148(2):147-159.

55. Thomas RE, Wilson $D$, Sheps $S$ : A literature review of randomized controlled trials of the organization of care at the end of life. Can J Aging 2006, 25(3):271-293.

56. Zimmermann C, Riechelmann R, Krzyzanowska M, Rodin G, Tannock I: Effectiveness of specialized palliative care: a systematic review. JAMA 2008, 299(14):1698-1709

57. Doug M, Adi Y, Williams J, Paul M, Kelly D, Petchey R, Carter YH: Transition to adult services for children and young people with palliative care needs: a systematic review. Arch Dis Child 2011, 96(1):78-84.

58. Harding R, Karus D, Easterbrook P, Raveis VH, Higginson IJ, Marconi K: Does palliative care improve outcomes for patients with HIV/AIDS? A systematic review of the evidence. Sex Transm Infect 2005, 81(1):5-14

59. Sampson EL, Ritchie CW, Lai R, Raven PW, Blanchard MR: A systematic review of the scientific evidence for the efficacy of a palliative care approach in advanced dementia. Int Psychogeriatr 2005, 17(1):31-40.

60. Johnston B: UK telehealth initiatives in palliative care: a review. Int J Palliat Nurs 2011, 17(6):301-308.

61. Lindstrom KB, Melnyk BM: Interventions for family caregivers of loved ones on hospice: a literature review with recommendations for clinical practice and future research. J Hosp Palliat Nurs 2009, 11(3):167-178.

62. Mitchell GK, Tieman JJ, Shelby-James TM: Multidisciplinary care planning and teamwork in primary care. Med J Aust 2008, 188(8 Suppl):S61-S64.

63. Shaw KL, Clifford C, Thomas K, Meehan H: Review: improving end-of-life care: a critical review of the gold standards framework in primary care. Palliat Med 2010, 24(3):317-329.

64. Aiken LS, Butner J, Lockhart CA, Volk-Craft BE, Hamilton G, Williams FG: Outcome evaluation of a randomized trial of the PhoenixCare intervention: program of case management and coordinated care for the seriously chronically ill. J Palliat Med 2006, 9:111-126.

65. Bakitas M, Lyons KD, Hegel MT, Balan S, Barnett KN, Brokaw FC, Byock IR, Hull JG, Li Z, McKinstry E, Seville JL, Ahles TA: The project ENABLE ॥ randomized controlled trial to improve palliative care for rural patients with advanced cancer: baseline findings, methodological challenges, and solutions. Palliat Support Care 2009, 7:75-86

66. Bakitas M, Lyons KD, Hegel MT, Balan S, Brokaw FC, Seville J, Hull JG, Li Z Tosteson TD, Byock IR, Ahles TA: Effects of a palliative care intervention on clinical outcomes in patients with advanced cancer: the Project ENABLE II randomized controlled trial. JAMA 2009, 302:741-749.

67. Mitchell GK, Del Mar CB, O'Rourke PK, Clavarino AM: Do case conferences between general practitioners and specialist palliative care services improve quality of life? A randomised controlled trial (ISRCTN 52269003). Palliat Med 2008, 22:904-912

68. Cheung W, Aggarwal G, Fugaccia E, Thanakrishnan G, Milliss D, Anderson R, Stock D, Bird H, Tan J, Fryc AC: Palliative care teams in the intensive care unit: a randomised, controlled, feasibility study. Crit Care Resusc 2010, 12:28-35.

69. Gade G, Venohr I, Conner D, McGrady K, Beane J, Richardson RH, Williams MP, Liberson M, Blum M, Della Penna R: Impact of an inpatient palliative care team: a randomized control trial. J Palliat Med 2008, 11:180-190.

70. Paes P: A pilot study to assess the effectiveness of a palliative care clinic in improving the quality of life for patients with severe heart failure. Palliat Med 2005, 19:505-506.

71. Sampson EL, Jones L, Thuné-Boyle IC, Kukkastenvehmas R, King M, Leurent B, Tookman A, Blanchard MR: Palliative assessment and advance care planning in severe dementia: an exploratory randomized controlled trial of a complex intervention. Palliat Med 2011, 25:197-209.

72. Temel JS, Greer JA, Muzikansky A, Gallagher ER, Admane S, Jackson VA Dahlin CM, Blinderman CD, Jacobsen J, Pirl WF, Billings JA, Lynch TJ: Early palliative care for patients with metastatic non-small-cell lung cancer. $N$ Engl J Med 2010, 363(8):733-742.

73. Agency for Healthcare Research and Quality: US Preventive Services Task Force Procedure manual. Rockville, MD: AHRQ; 2008

74. Heart Foundation: Multidisciplinary Care for People with Chronic Heart Failure: Principles and Recommendations for Best Practice. Canberra: National Heart Foundation of Australia; 2010

75. Davison SN: Integrating palliative care for patients with advanced chronic kidney disease: recent advances, remaining challenges. J Palliat Care 2011, 27(1):53-61.

76. Tamura MK, Cohen LM: Should there be an expanded role for palliative care in end-stage renal disease? Curr Opin Nephrol Hypertens 2010, 19(6):556-560.

77. Ram FSF, Wedzicha JA, Wright J, Greenstone M: Hospital at home for patients with acute exacerbations of chronic obstructive pulmonary disease: systematic review of evidence. BMJ 2004, 329(7461):315.

78. Mitchell SL, Black BS, Ersek M, Hanson LC, Miller SC, Sachs GA, Teno JM, Morrison RS: Advanced dementia: state of the art and priorities for the next decade. Ann Intern Med 2012, $156(1$ Pt 1):45-51.

79. Canada H: Canadian Strategy on Palliative and End-of-Life Care - Final Report of the Coordinating Committee. Ottawa, Ontario: Health Canada; 2007.

80. Department of Health and Children: Report of the National Advisory Committee on Palliative Care. Dublin: Department of Health and Children; 2001.

81. New Zealand Ministry of Health: The New Zealand Palliative Care Strategy. Wellington: New Zealand Ministry of Health; 2001.

82. Rabow MW, Dibble SL, Pantilat SZ, McPhee SJ: The comprehensive care team: a controlled trial of outpatient palliative medicine consultation. Arch Intern Med 2004, 164:83-91.

83. Sudore RL, Schickedanz AD, Landefeld CS, Williams BA, Lindquist K, Pantilat SZ, Schillinger D: Engagement in multiple steps of the advance care planning process: a descriptive study of diverse older adults. J Am Geriatr Soc 2008, 56(6):1006-1013.

84. Manfredi PL, Morrison RS, Morris J, Goldhirsch SL, Carter JM, Meier DE: Palliative care consultations: how do they impact the care of hospitalized patients? J Pain Symptom Manage 2000, 20(3):166-173.

85. Hanks G, Robbins M, Sharp D, Forbes K, Done K, Peters T, Morgan H, Sykes J, Baxter K, Corfe F: The imPaCT study: a randomised controlled trial to evaluate a hospital palliative care team. Br J Cancer 2002, 87(7):733-739.

86. Higginson I, Finlay I, Goodwin D: Is there evidence that palliative care teams alter end-of-life experiences of patients and their caregivers? J Pain Symptom Manage 2003, 25(2):150-168.

87. Morrison RS, Penrod JD, Cassel JB, Caust-Ellenbogen M, Litke A, Spragens L, Meier DE, Palliative Care Leadership Centers' Outcomes G: Cost savings associated with US hospital palliative care consultation programs. Arch Intern Med 2008, 168(16):1783-1790.

88. Penrod JD, Deb P, Dellenbaugh C, Burgess JF Jr, Zhu CW, Christiansen CL, Luhrs CA, Cortez T, Livote E, Allen V, Morrison RS: Hospital-based palliative care consultation: effects on hospital cost. J Palliat Med 2010, 13(8):973-979.

89. Morrison RS, Maroney-Galin C, Kralovec PD, Meier DE: The growth of palliative care programs in United States hospitals. J Palliat Med 2005, 8(6):1127-1134

90. Gruneir A, Silver MJ, Rochon PA: Review: Emergency Department Use by Older Adults: a literature review on trends, appropriateness, and consequences of Unmet Health Care Needs. Med Care Res Rev 2011, 68(2):131-155.

91. Beynon T, Gomes B, Murtagh FEM, Glucksman E, Parfitt A, Burman R, Edmonds P, Carey I, Keep J, Higginson IJ: How common are palliative care needs among older people who die in the emergency department? Emerg Med J 2011, 28(6):491-495. 
92. Forero R, McDonnell G, Gallego B, McCarthy S, Mohsin M, Shanley C, Formby F, Hillman K, Palliative Care Leadership Centers' Outcomes G: A literature review on care at the end-of-life in the Emergency Department. Emerg Med Inter 2012. doi:10.1155/2012/486516.

93. Agarwal S, Banerjee J, Baker R, Conroy S, Hsu R, Rashid A, CamossoStefinovic J, Sinfield P, Habiba M: Potentially avoidable emergency department attendance: interview study of patients' reasons for attendance. Emerg Med J 2011. doi:10.1136/emermed-2011-200585.

94. Christakis DA, Mell L, Koepsell TD, Zimmerman FJ, Connell FA: Association of lower continuity of care with greater risk of emergency department use and hospitalization in children. Pediatrics 2001, 107(3):524-529.

95. Kushel MB, Perry S, Bangsberg D, Clark R, Moss AR: Emergency department use among the homeless and marginally housed: results from a community-based study. J Inform 2002, 92(5):778-784

96. Ginde AA, Lowe RA, Wiler JL: Health Insurance Status Change and Emergency Department Use Among US Adults. Arch Intern Med 2012, 172(8):642-647. archinternmed. 2012.2034 v2011.

97. McAlister FA, Stewart S, Ferrua S, McMurray JJJV: Multidisciplinary strategies for the management of heart failure patients at high risk for admission: a systematic review of randomized trials. J Am Coll Cardiol 2004, 44(4):810-819.

98. Richardson DB: Emergency department targets: a watershed for outcomes research? Med J Aust 2012, 196(2):126-127.

99. Teno JM: Now is the time to embrace nursing homes as a place of care for dying persons. J Palliat Med 2003, 6(2):293-296.

100. Casarett D, Karlawish J, Morales K, Crowley R, Mirsch T, Asch DA: Improving the use of hospice services in nursing homes: a randomized controlled trial. JAMA 2005, 294:211-217.

101. Kovach CR, Wilson SA, Noonan PE: The effects of hospice interventions on behaviors, discomfort, and physical complications of end stage dementia nursing home residents. Am J Alzheimers Dis Other Demen 1996, 11(4):7-15.

102. Hanson LC, Reynolds KS, Henderson M, Pickard MD: A quality improvement intervention to increase palliative care in nursing homes. J Palliat Med 2005, 8(3):576-584

103. Coleman EA: Falling through the cracks: challenges and opportunities for improving transitional care for persons with continuous complex care needs. J Am Geriatr Soc 2003, 51(4):549-555.

104. Agar M, Currow DC, Shelby-James TM, Plummer J, Sanderson C, Abernethy AP: Preference for place of care and place of death in palliative care: are these different questions? Palliat Med 2008, 22(7):787-795.

105. Burns CM, Dixon T, Smith WT, Craft PS: Patients with advanced cancer and family caregivers' knowledge of health and community services: a longitudinal study. Health Soc Care Community 2004, 12(6):488-503.

106. Hines S, McCrow J, Abbey J, Footit J, Wilson J, Franklin S, Beattie E: Effectiveness and Appropriateness of a Palliative Approach to Care for People with Advanced Dementia: A Systematic Review. Brisbane: Dementia Collaborative Research Centre for carers and consumers, QUT; 2009.

107. Andrews J, Christie J: Emergency care for people with dementia Emerg Nurse 2009, 17(5):12.

108. Mead N, Bower P: Patient-centredness: a conceptual framework and review of the empirical literature. Soc Sci Med 2000, 51(7):1087-1110.

109. Trivedi D, Goodman C, Gage H, Baron N, Scheibl F, lliffe S, Manthorpe J, Bunn F, Drennan V: The effectiveness of inter-professional working for older people living in the community: a systematic review. Health Soc Care Community 2013, 21(2):113-128.

110. Health NSW: Paediatric Palliative Care Planning Framework 2011-2014. Sydney: NSW Government; 2011.

111. Vickers J, Thompson A, Collins GS, Childs M, Hain R: Place and provision of palliative care for children with progressive cancer: a study by the Paediatric Oncology Nurses' Forum/United Kingdom Children's Cancer Study Group Palliative Care Working Group. J Clin Oncol 2007, 25(28):4472-4476.

112. Scullion F: An integrated model of care is needed for children and young people with cancer. Int J Palliat Nurs 2005, 11(9):494-495

113. Gruen RL, Weeramanthri TS, Knight SE, Bailie RS: Specialist Outreach Clinics in Primary Care and Rural Hospital Settings. In Cochrane Database of Systematic Reviews. Chichester: John Wiley \& Sons, Ltd; 2003

114. Broadbent A, McKenzie J: Wagga Wagga specialist outreach palliative medicine service: a report on the first 12 months of service. Aust J Rural Health 2006, 14(5):219-224.

115. Scott C, Hofmeyer A: Networks and social capital: a relational approach to primary healthcare reform. Health Res Policy Syst 2007, 5:9.
116. Baker CD, Lorimer AR: Cardiology: the development of a managed clinical network. BMJ 2000, 321(7269):1152-1153.

117. Managed clinical networks - a literature review. [http://www.canceraustralia. gov.au/media/13098/managed\%20clinicial\%20networks,\%20cannet\% 20literature\%20review.pdf]

118. Department of Health: End of Life Care Strategy -Promoting High Quality Care for All Adults at the End of Life. London: Department of Health; 2008.

119. National Health and Hospitals Reform Commission: A Healthier Future for All Australians - Final Report. Canberra: Department of Health and Ageing; 2009.

120. Noble B, Hughes P, Ingleton C, Clark D: Rural palliative care needs: a survey of primary care professionals in Powys, Wales. Int J Palliat Nurs 2001, 7(12):610-615.

121. Masso M, Owen A: Linkage, coordination and integration: evidence from rural palliative care. Aust J Rural Health 2009, 17(5):263-267.

122. Mitchell GK: How well do general practitioners deliver palliative care? A systematic review. Palliat Med 2002, 16(6):457-464.

123. Ahmed N, Bestall JC, Ahmedzai SH, Payne SA, Clark D, Noble B: Systematic review of the problems and issues of accessing specialist palliative care by patients, carers and health and social care professionals. Palliat Med 2004, 18(6):525-542.

124. Shipman C, Gysels M, White P, Worth A, Murray SA, Barclay S, Forrest S, Shepherd J, Dale J, Dewar S, Peters M, White S, Richardson A, Lorenz K, Koffman J, Higginson IJ: Improving generalist end of life care: national consultation with practitioners, commissioners, academics, and service user groups. BMJ 2008, 337:a1720.

125. Low JA, Liu RK, Strutt R, Chye R: Specialist community palliative care services-a survey of general practitioners' experience in Eastern Sydney. Support Care Cancer 2001, 9(7):474-476.

126. Mulvihill C, Harrington A, Robertson A: A literature review of the role of the specialist palliative care community nurse. Int J Palliat Nurs 2010, 16(4):163-172.

127. Robinson CA, Pesut $B$, Bottorff $J$ : Issues in rural palliative care: views from the countryside. J Rural Health 2010, 26(1):78-84.

128. Evans R, Stone D, Elwyn G: Organizing palliative care for rural populations: a systematic review of the evidence. Fam Pract 2003, 20(3):304-310.

129. Claxton-Oldfield S, Claxton-Oldfield J: Should I Stay or Should I Go: A Study of Hospice Palliative Care Volunteer Satisfaction and Retention. Am J Hosp Palliat Care 2012, 29(7):525-530.

130. Claxton-Oldfield S, Gosselin N, Claxton-Oldfield J: Imagine you are dying: would you be interested in having a Hospice Palliative Care volunteer? Am J Hosp Palliat Med 2009, 26(1):47-51.

131. Watts JH: The place of volunteering in Palliative Care. In Contemporary and Innovative Practice in Palliative Care. InTech online. Edited by Chang $\mathrm{E}_{\text {, }}$ Johnson A. :83-102.

132. Hynson J, Drake R: Paediatric Palliative Care in Australia and New Zealand. In Paediatric Palliative Care: Global perspectives. Edited by Knapp C, Madden V, Fowler-Kerry S. New York: Springer Dordrecht; 2012:379-402.

133. Wee B, Hadley G, Derry S: How useful are systematic reviews for informing palliative care practice? Survey of 25 Cochrane systematic reviews. BMC Palliat Care 2008, 7:13.

134. Gomez-Batiste X, Tuca A, Corrales E, Porta-Sales J, Amor M, Espinosa J, Borras $J M$, de la Mata I, Castellsague X: Resource consumption and costs of palliative care services in Spain: a multicenter prospective study. J Pain Symptom Manage 2006, 31(6):522-532.

135. Fassbender $K$, Fainsinger $R$, Brenneis $C$, Brown $P$, Braun $T$, Jacobs $P$ : Utilization and costs of the introduction of system-wide palliative care in Alberta, 1993-2000. Palliat Med 2005, 19(7):513-520.

136. Gomez-Batiste X, Caja C, Espinosa J, Bullich I, Porta-Sales J, Sala C, Limon E, Trelis J, Pascual A, Luisa Puente M, Working Group of Standing Advisory Committee for Palliative Care: Quality improvement in palliative care services and networks: preliminary results of a benchmarking process in Catalonia, Spain. J Palliat Med 2010, 13(10):1237-1244.

137. Gomes B, Calanzani N, Curiale V, McCrone P, Higginson IJ: Effectiveness and cost-effectiveness of home palliative care services for adults with advanced illness and their caregivers. Cochrane Database Syst Rev 2013, 6:CD007760.

138. Smith S, Brick A, O'Hara S, Normand C: Evidence on the cost and costeffectiveness of palliative care: A literature review. Palliat Med 2014, 28(2):130-150

139. Egger M, Smith GD: Bias in location and selection of studies. BMJ 1998, 316(7124):61-66 
140. Tieman JJ, Abernethy A, Currow DC: Not published, not indexed: issues in generating and finding hospice and palliative care literature. J Palliat Med 2010, 13(6):669-675.

141. Schunemann HJ, Fretheim A, Oxman AD: Improving the use of research evidence in guideline development: 1 Guidelines for guidelines. Health Res Policy Syst 2006, 4:13

142. Currow D, Tieman J, Green A, Zafar SY, Wheeler JL, Abernethy AP: Refining a checklist for reporting patient populations and service characteristics in Hospice and Palliative Care Research. J Pain Symptom Manag 2012, 43(5):902-910.

143. Craig P, Dieppe P, Macintyre S, Michie S, Nazareth I, Petticrew M, Medical Research Council G: Developing and evaluating complex interventions: the new Medical Research Council guidance. BMJ 2008, 337:a1655.

144. Stiel S, Pastrana T, Balzer C, Elsner F, Ostgathe C, Radbruch L: Outcome assessment instruments in palliative and hospice care-a review of the literature. Support Care Cancer 2012, 20(11):2879-93.

145. Smith TA, Davidson PM, Lam LT, Jenkins CR, Ingham JM: The use of noninvasive ventilation for the relief of dyspnoea in exacerbations of chronic obstructive pulmonary disease; a systematic review. Respirology 2012, 17(2):300-307.

146. McMillan SC, Small BJ, Haley WE: Improving hospice outcomes through systematic assessment: a clinical trial. Cancer Nurs 2011, 34(2):89-97.

147. Currow DC, Agar MR, To THM, Rowett D, Greene A, Abernethy AP: Adverse events in hospice and palliative care: a pilot study to determine feasibility of collection and baseline rates. J Palliat Med 2011, 14(3):309-314

148. Kamal AH, Currow DC, Ritchie C, Bull J, Wheeler JL, Abernethy AP: The value of data collection within a palliative care program. Curr Oncol Rep 2011, 13(4):308-315.

149. El-Jawahri A, Greer JA, Temel JS: Does palliative care improve outcomes for patients with incurable illness? A review of the evidence. J Support Oncol 2011, 9(3):87-94.

150. Harding R, Simon ST, Benalia H, Downing J, Daveson BA, Higginson IJ, Bausewein C, PRISMA: The PRISMA Symposium 1: outcome tool use. Disharmony in European outcomes research for palliative and advanced disease care: too many tools in practice. J Pain Symptom Manage 2011, 42(4):493-500

151. Campbell M, Fitzpatrick R, Haines A, Kinmonth AL, Sandercock P, Spiegelhalter D, Tyrer P: Framework for design and evaluation of complex interventions to improve health. BMJ 2000, 321(7262):694-696.

doi:10.1186/1472-6963-14-136

Cite this article as: Luckett et al:: Elements of effective palliative care

models: a rapid review. BMC Health Services Research 2014 14:136.

\section{Submit your next manuscript to BioMed Central and take full advantage of:}

- Convenient online submission

- Thorough peer review

- No space constraints or color figure charges

- Immediate publication on acceptance

- Inclusion in PubMed, CAS, Scopus and Google Scholar

- Research which is freely available for redistribution 